\title{
البيئة الثقافية وأثرها على نتاج الخزف العراقي المعاصر
}

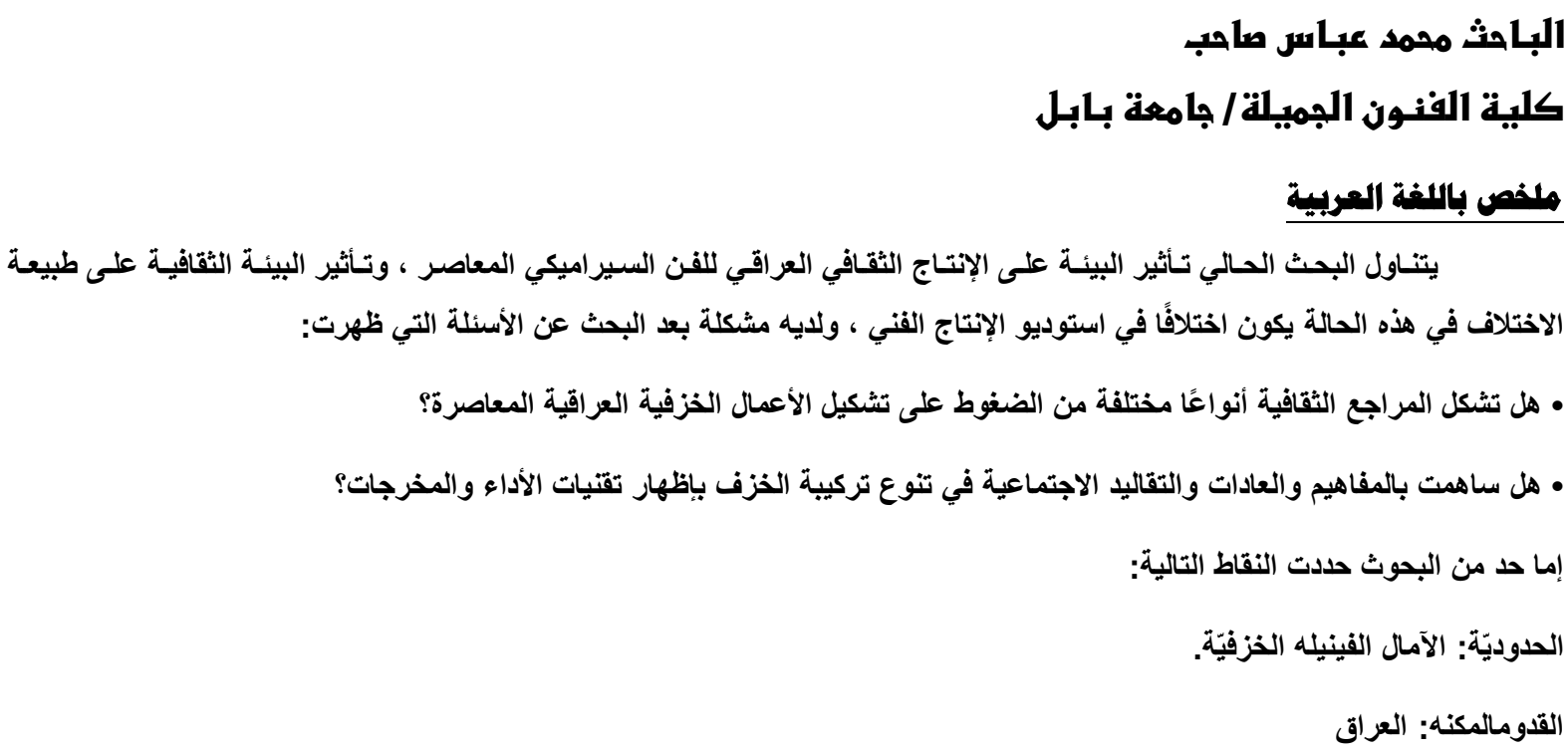

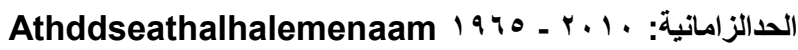

* أما فيما يتعلق بتحديد المصطحات ، فقد تضمن مفهوم (البيئة) من حيث علاقتها وعلاقتها بالبحث الحالي وعلامة (البيئة الثقافية وتأثيرها. على الخزف العر اقي المعاصر).

• يككون الفصل الثاني من ثلاثة أقسام (البيئة الثقافية والخصائص في المجتمح). القسم الثاني (البيئة الثقافية وآلية التوظيف في الخزف (العر اقي المعاصر) • شملت إجراءات البحث في الفصل الثالث مجتمع البحث الذي شمل (190) وفقاً لفناتين خوزفيا العراقيين ، وعينة وكنلك منهجية بحث وصفية وتحليلية وأخيرًا تحليل عينة البحث. • الفصل الرابع الذي ظهر نتائج البحث الأكثر أهية قسم من البيئة الثقافية المحلية المؤثرة التمثيله بشعبية تراثية ظهرت أعمال سير اميك (قوم) نثأت من القيم الروحية شكلت انعكاسا للتقاليد

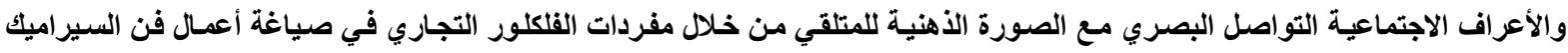

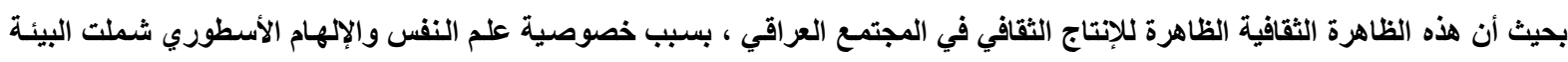
الثقافية للواقع الفيزيائي المحلي ظهرت مفردات المفردات Aelchenachel domes and Doors ، وغير ها من الألوان ، فقد عبرت عن مثاعرها وجمالها قيم تاجمحييكلكله عليكم اليونيكونزلوه التراث الثعبي المحلي للعراق. عرضت مجموعة من الأعمال الخزفية المستمدة من التراث الثقافي القديم في بلاد مـا بين النهرين ، وشكلت الفن السومري التـاريخي

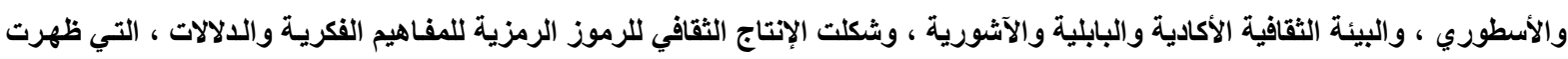
من خلال روئة البيئة الميتافيزيقية الأسطورية الحضارة العراقية القيدة. الاستتتاجات النهائية وقائمة المصادر العربية والأجنبية

Research Summary

The present research deals with the impact of the environment on the Iraqi cultural production of contemporary ceramic art, and the impact of the cultural environment on the nature of the difference. In this case, there is a difference in the studio of artistic production.

-Are cultural references different types of pressure on the formation of contemporary Iraqi ceramics? 
- Have you contributed to the concepts, customs and social traditions in the diversity of porcelain composition by showing the techniques of performance and output?

Either a limit of research identified the following points:

Borderline: Vesicular-Colloidal Expectations.

Arrival: Iraq

Hemorrhoids: Athddseathalhalemenaam 1970 - r..

As for the definition of terminology, it included the concept of "environment" in relation to its relation to current research and the mark (cultural environment and its impact on contemporary Iraqi ceramics.(

-The second chapter consists of three sections (the cultural environment and the characteristics of society). Section II (Cultural environment and the mechanism of employment in contemporary Iraqi ceramics(

-The research procedures in the third chapter included the research community, which included (190) according to the Iraqi artists of Khuzia, and a sample as well as descriptive and analytical research methodology and finally analysis of the research sample.

-Chapter s shows the most important search results

A section of the influential local cultural environment represented by popular heritage. The works of ceramics emerged from the spiritual values which formed a reflection of the social traditions and customs. Visual communication with the mental image of the recipient through the vocabulary of commercial folklore in the formulation of works of ceramic art so that this phenomenon is cultural phenomenon of cultural production in society Iraqi, because of the privacy of psychology and legendary inspiration included the cultural environment of local physical reality appeared vocabulary vocabulary Aelchenachel domes and Doors and other colors, has expressed its feelings and beauty values Tajmihilk you Alonikonzloh heritage To the local people of Iraq.

A collection of ceramic works derived from the ancient cultural heritage of Mesopotamia was presented. It formed Sumerian historical and mythological art, the oppressive cultural environment, Babylonian and Assyrian, and formed the cultural production of symbolic symbols of intellectual concepts and connotations, which emerged through the vision of the legendary metaphysical environment of ancient Iraqi civilization.

Final conclusions and a list of Arab and foreign sources

الفصل الاول- همددات البحث

O مشكلة البحث: تعد "البيئة" بمختلف مسمياتها من العو امل المهمة التي تحيط بالفنـان بشكل رئيسي في

تعزيز مدركاته الحسية والابداعية ، فـالبيئة تشكل مصدرا مباشرا في تعزز قدرات الفنان الفكريـة والمعرفية

من خلال ما يقوم في إطار صياغة كل بحيطه من بيئات في انتاج أعمـال فنيـة اتسمت بالمحاكاة و التقليد من

جهة و إعادة صياغة الموضو عات من خلال التجديد والابتكار من جهة اخرى، مما أعطى للفنان مفاتيح التعبير

بالتجريب في الفكر .. ومن هنا اختلف مفهوم الأشـال الفني و الجمـالي و علاقته بالبيئة الثقافيـة المحيطـة بالفنـان

ذاتهه من خلالهـا يمكن تحقيق المفاهيم و الأفكار و الفلسفات و القيم التعبيريـة والتشكيلية , التي تجعل من الفن

رسالة هامة، فبالإضـافة لكون "البيئة" نقطة تحول من المشغولة التقليديـة إلى العمـل الفني المفـاهيمي كذلك يعد

مفهوم البيئـة الثقافيـة مقياسـاً للنضــج العقلى و التحـرر الفكـري مدـا أدى إلىى تغيـر الرؤيسة التعبيريـة المفـاهيم

و العادات و التقاليد الاجتماعية وطرق توظيفها في العمل الفني, لذلك أصبحت البيئة الثقافية مدخلاً هامـاً في بناء

العمل الفني المعاصر . وعليه فمثكلة البحث الحالي ترتبط بمرجعيات البيئة الاجتماعية و السياسية و الاقتصـادية

التي نتكل ضناغطا مباشر ا على النتاج الفني التشكيلي الخزفي التي اختلفت وتضـايفت بشكل كبير في الخزف 
لذلك يمكن تحديد مشكلة البحث الحالي بالأسئلة الآتية:-

هل شكلت المرجعيات التقافية باختلاف أنو اعها ضاغطاً على تشكيل الاعمال الخزفية العر اقيـة المعاصرة و أسـهمت المفـاهيم والعـادات و التقاليد الاجتماعية في تنوع التتكيل الخزفي من خـلال اظهار تقنيات الاداء

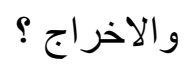

م اهمية البحث : انه يمثل إسهاما معرفيا في عرض المفاهيم والأفكار الثقافات المحلية في فن الخزف ، ومدى تأثيره بظو اهر البيئة المحيطة بالفنان ( الاجتماعية والسياسية والاقتصادية ) .

م هدف البحث: هو الكثف عن المرجعيات البيئية الضاغطة ومدى تأثثير ها على الاعمال الفنية الخزفية . O مدود البحث:

$$
\begin{aligned}
& \text { الحدود الموضوعية : الاعمال الفنية الخزفية . } \\
& \text { الحدود المكانية : العراق . }
\end{aligned}
$$

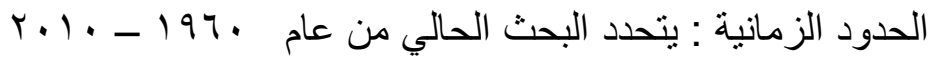

م تحديد المصطلحات:

• البيئة (Environment) يعرف (بدوي) البيئة بانها المجـال الذي تحدث فيـه الاثارة و التفاعل لكل وحدة حية، وهي كل ما يحيط بالانسان من طبيعة ومجتمعات بشرية ونظم اجتماعية و علاقات شخصية وهي المؤثر الذي يدفع الكائن الى الحركة والنشـاط و السعي لذلك فـان التفاعل منو اصل بين البيئة و الفرد فالاخذ بالعطاء مستمد متلاحق. ويضع (بدوي) تعريفه للبيئة في قسمين:

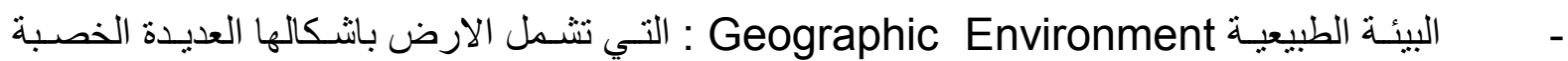
و الصحر اوية و الجبلية.. و وغير ها.

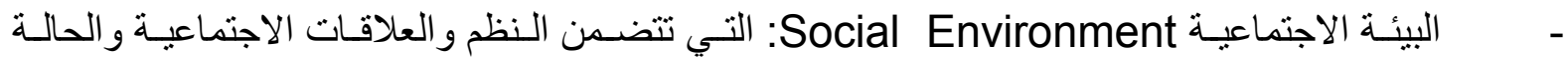
الاقتصادية و الصحية و التعليم.... وغير ها وجميعها متصلة ببعضها' . التعريف الاجر ائي فيعرف الباحث : بانها نظام متكامل يتألف من مجموعة العو امل و العناصر الطبيعية والاجتماعيـة والاقتصـادية و الحضـارية التي تحيط بالانسان ويحيا بها.

\section{الفصل الثاني- الاطار النظري}

المبحث الاول : البيئة الثقافية وسماتها في المجتمع :

أعطى مفهوم " البيئة " في شتى مناحى المعرفة الإنسانية , علماً وفلسفة وأدباً وتربيـة وثقافة، ويرتبط مدلولها بالنشاطات البشرية المختلفة، كونها محركاً مهيمناً للحضارة وكذلك تدخل ضمن الركائز الاساسية لها ، و عليه يمكن أن نضع تعريف شامل للبيئة يستو عب مجالات استخدامها وسماتها الفنيـة والجماليـة، فالبيئة هي إدر الك العالم المحبط بالإنسـان بمفهوم خـاص بـه وحده, سو اء أكان هذا العـالم عبارة عن شكل، فكرة، حدث اجتماعي، أو معلومة علمية فهي بمثابـة الإطـار الذى يحبط بفاعليـة الانسـان او الفنان ويوجهها نحو التعرف 
على مزيد من العلاقات الثقافية والاجتماعية التي تنكل في حد ذاتها خبرة معينة في النتاجـات الفنية والادبيـة ,

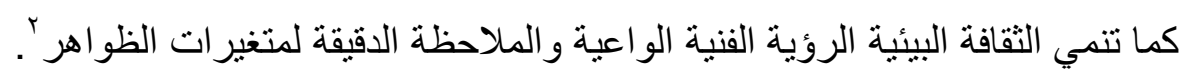
ويؤكد البروفيسور " روي هاريسون" ان البيئة الثقافية و علاقتها بـالمجتمع هي محصلة ارتباط وتفاعل في جميع عناصر ها وفنونها ومجالاتها المعرفية ، فـالثقافة التي نعيها تدعو إلى التجديد بمفهوم الفكر الإبداعي

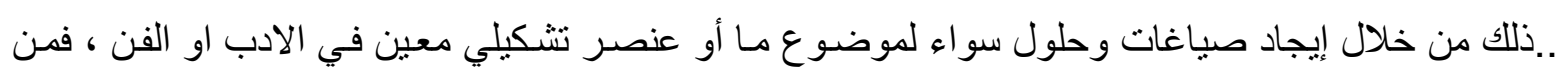
خلال الادر الك الفكري و المعرفة يمكن للفنان ان يبر هن على اهمية البيئة المحيطة التي من خلالها اصبح الفنـان

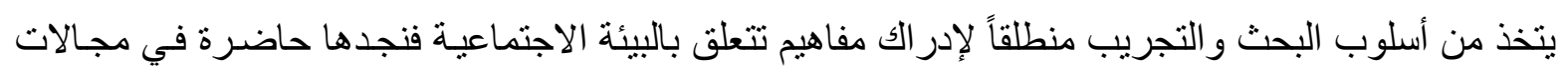
مختلفة كالتشكيل و المسرح و الموسيقى و الادب ، وذلك بهدف الكثف عن مظاهر وكيفيات اجتماعية لها دلالات

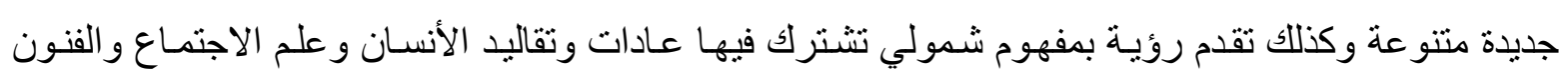
الجميلة ومن الأمثلة التي وتقت من تاريخ الأساطير القديمة، موضحاً أن تأثير البيئة جعل من الفن أكثر ارتباطياً بـالمجمع، حيث تغير مفهوم الفن من اتجاه ذاتي خاص بالفنان إلى اتجاه عام، فأصبح هناك تفاعل إيجابي, بين لإني الفنان و البيئة و المجتمع و الجمهور.

ومن هنا تبدو أهمية الدراسات العلمية للبيئة ومنها البيئة التقافية و التعرف من خلالها على العلاقات

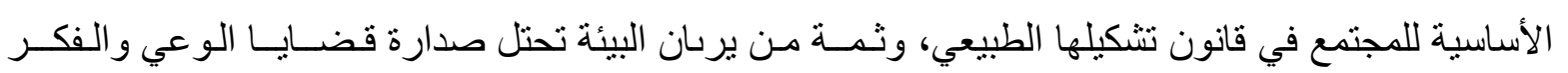
بمفهوم شامل ومنفتح.

فـالتقـافـة مفهوم يجمع ثمـار الفكر الإنساني ، فنـان وادبـاً، وعليه تُصور البيئة الثقافية كمنهج لفهم كيفية تكيف الإنسـان لمجموعة واسعة من البيئات في تغيير ثقافته ومنهجيته ،وفتح افاق التطور التي تغير ولته

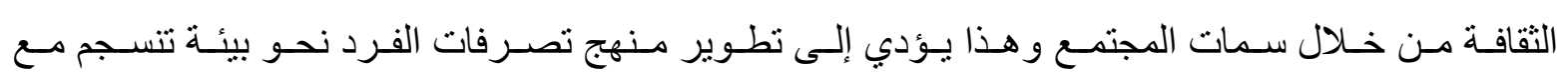
مجتمعه؛ ..حيث يجد بعض علماء الاجتماع مشكلة في ذلك خصوصاً أولئك الذين يكتبون من منظور ماركسي..

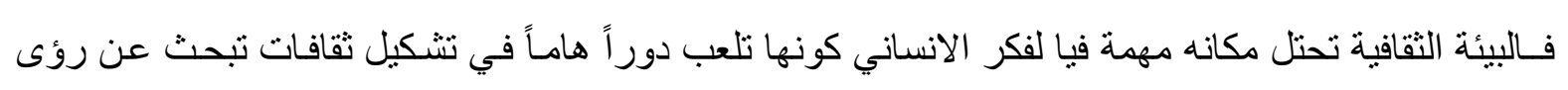
فنية جديدة. وتمشياً مع إدر اك أهمية( البيئة ) اتجاه حل المشاكل الاجتماعية والتي تواجه الطبيعة البشرية . أن أي تكيف بشري معين هو جزء مورّث تاريخي يتضمن تقنيات وممارسـات معرفية التي تسمح

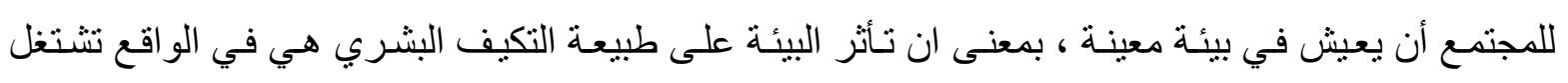

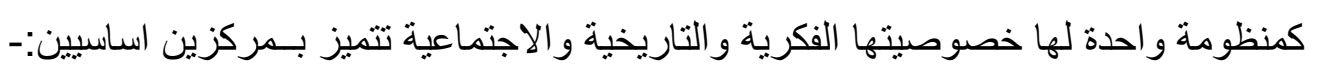
أولهما الصورة الذهني- وتتضمن المناهج والقيم الفكرية وما شابه ، التي تشكل بمجملها الجوهر الروحي لهويـة المجتمع (الهوية الحضارية) و هذا الإطار الذي يشكل المحرك الرئيسي للصورة الاسطورية المجتمعية ، ذلك من خلال التفاعل مع الظروف التي نطر أ على المجتمع التي كانت منوارثة من جيل الى جيل . 
وثانيهمـا الموروث الحضـاري النـاريخي- وهو الأطسار المجسم المسادي ويشـمل النتاجـات والممتلكات المتعلقة

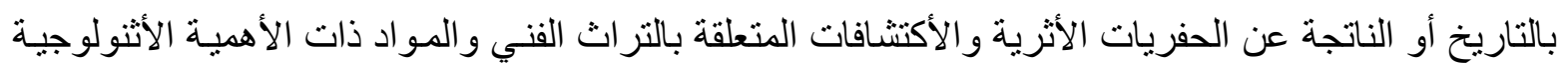

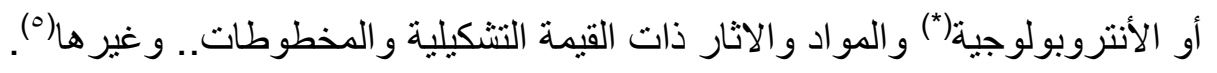

اذا التصور الأول ير اه تر اكمياً من الصورة الذهنية الأسطورية لأشكال الوعي تتجلى في تصورات

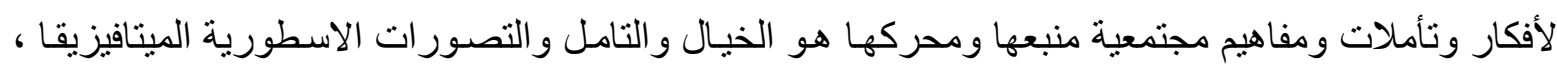
كونها هي الخالقة للموضو عات والقيم الر اسخة في مخيلة المجتمع.

التصدور الثاني للتراث يقوم على المفهوم المادي الوقعي للتاريخ، وهي العلاقة بين الوعي الأجتماعي و الوجود الأجتماعي و هذا المفهوم يرى في التراث شكلاً متكاملاً والهدف منه منطق يستمد التراث في رحلتها من الماضي الى الحاضر (`).

ان الضاغط في البنية الثقافية و الفنية للمجتمع يتعين أن تكون مبنية من مفاهيم ومعطيات بيئية ناتجـة

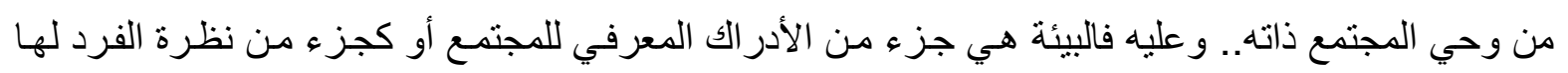
نحو ما يدور من حوله من قضايا ومشكلات اهمها ما يخص الجانب الاقتصادي او السياسي، وهذه النظرة لها

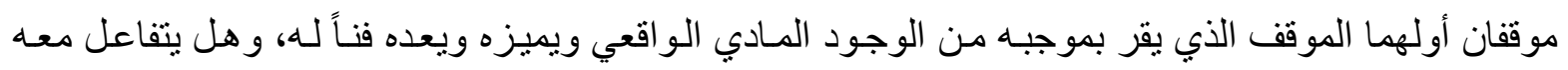

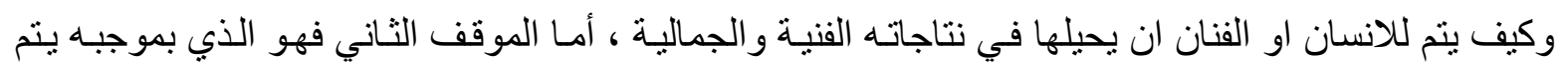
إدخال سمات التراث وتفاعله في الأنتاج الفني ، ومن ثم النظر الى هذا الوجود المـادي ذاتياً سواء كانت هذه ونه

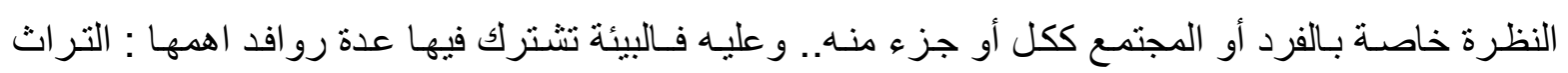
الثعبي Folklore ويرتكز الفلكلور على فكرة المجتمع في مقابلة النزعة الفردية وتعدد المعاني لمفهوم البيئة

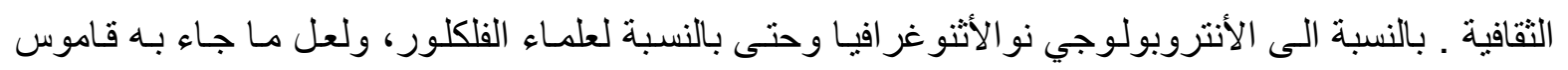

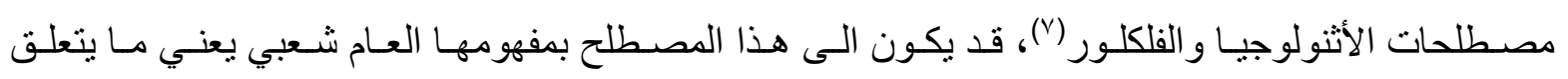
بمجمو عـة بشرية يرتبط أفر ادهـا بتر اث مشترك وشعور خاص بالتعاطف قائم على خلفية تاريخية مشتركة تعيش ضمن حدود معينة تفصلها عن الجماعات الأخرى حدود سياسية وثقافية نتيجة لعو امل جغر افية ودينية ولغوية و أقتصادية وعرقية ..بمعنى ان تلك الجماعة هي المحرك و المؤسس في تكوين الحضـارة ، وتميز هـا

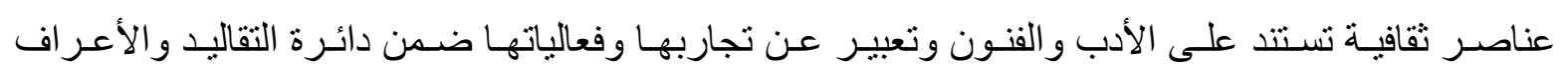

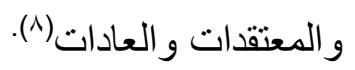

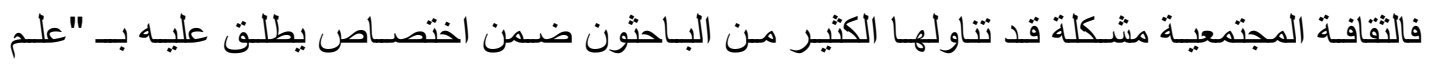

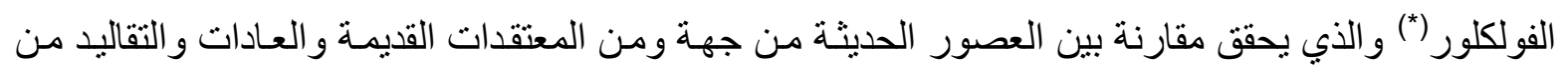

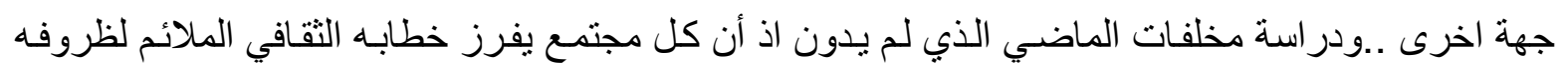
التاريخية وثقل تقاليده ولحاجاته المادية والروحية وفقا لنقافته الثعبية، اذا الفلكلور هو تعبير عن أنفعال عاطفي أو فكري يتخذ اللهجة العامية الدارجة أسلوباً مميز في التعبير الفني، و التي يتميز بها الفنان في نتاجاتـه الذي ولي

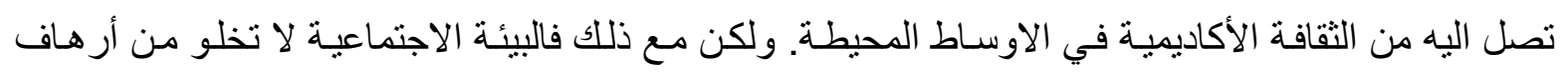


الحس وبر اءة العفويـة في أطلاق المشـاعر والأحاسيس وصدق يتجلى في رسم الصسورة للبيئسة الاجتماعيـة و الفكرية (9).

ومن سمات البيئة الثقافية الثعبية هو التداول الجماعي والتناقل الثفهي، والتداول يضفي على التراث الثعبي قاطبة روحسه وطبيعته المميزة، فضـلا" عن مجهولية (المؤلف) أو المبدع الأول، وهي أحدى نتائج

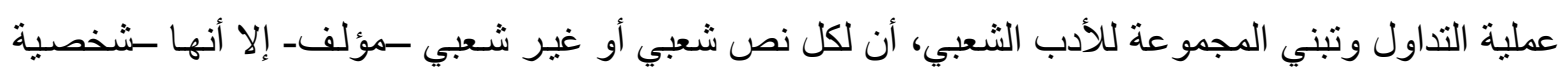

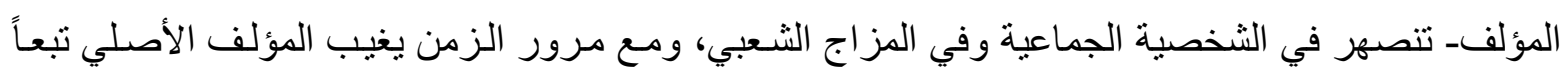
لذللك و عندما تتناول المجمو عة العمل الأدبي (الثـعبي) يتعرض للتحرير و التبديل عبر رحلة الزمان و المكان وتبث فيه بعضاً من خصائصها فتلمس فيه الروح الجماعية و المضمون التقليدي (النسق المـألوف) و على الرغم

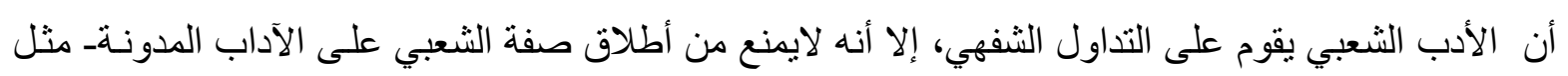

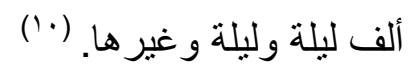

ونجد ايضا ضمن طيات البيئة الثقافية المثل او الامثال الثـعبية وهي صيغة شعبية مو غلة يستخدمها الأنسان الثعبي في حياته اليومية وهو مصطلح يدل على جنس أدبي شائع يوجد في تراث الأمم والثعوب على على

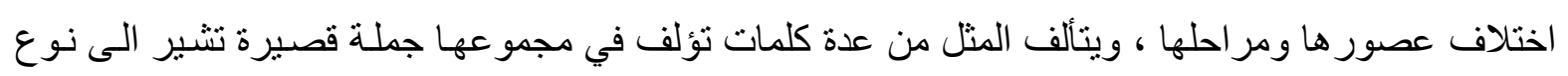
من السلوك له معنى أوسع من الخبرة أو الموقف المعين الذي تنشير اليه الألفاظ، فهو يشير الى مفهوم مجرد يتمكن الفرد من فهمه واستعماله بعد أن يكون قد تخطى مرحلة معينة من مر احل نموه المعرفي وتؤلف الأمثنال

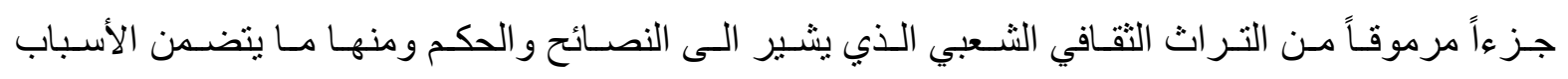
و التفسير ات لسلوك معين. وهي "تعبير عن واقع معين في ظرف معين ينبع من البيئة ويتأثر بجوانب الحياة

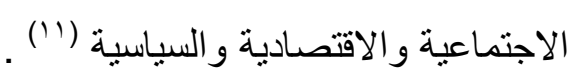

فلابد من الاشارة الى ان المعتقدات الدينية هي سلوك اجتمـاعي لا ينفصل عن البيئة الثقافية، بحكم

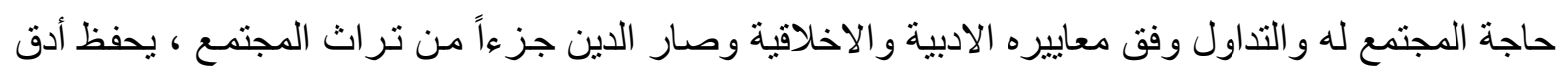

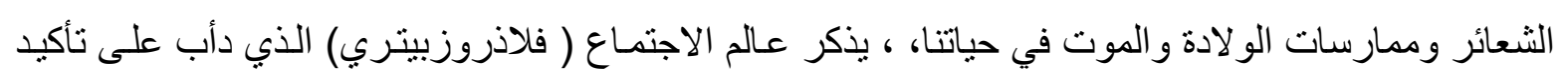

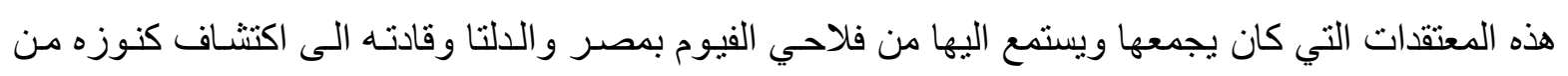

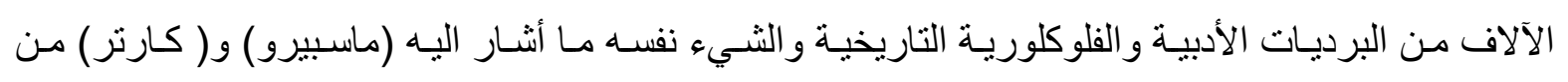

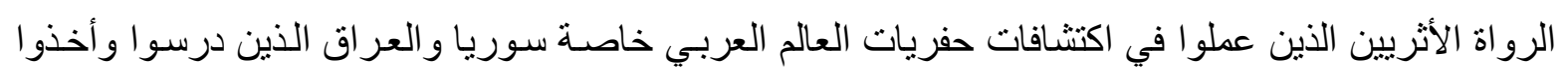
حتى من -ألف ليلة وليلةـ و النصوص الثفهية لفلاحي العراق (r') والتي كانت لها الاثر الكبير في نتاجات الكثير من الادباء والمفكرين و الفنانين لان التراث و الموروث جزء لا يتجزء من فكر ومخيلة الانسـان و الفنـان على حدا سواء.

كما هو واضح أن المعتقدات الدينية تستند في أغلب الأحيان الى الفكر والقيم وكذلك على المعتقدات

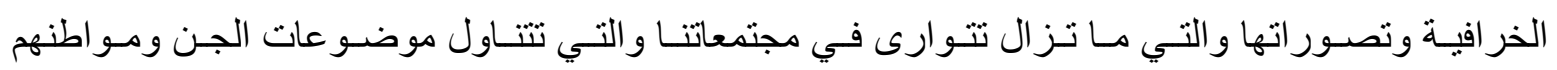
ومصـاهرتهم للأنس وقبائلهم الغيلان، السـعالي أو السعلوة و العفاريت و النتر اهـات وسكان مـا تحت الأرض. 
الخ، يرجعها علماء الفولكلور منذ الألف الرابع قبل الميلاد، وبشكل أخص سكان الجنوب، اليمن، القحطانيين. حيث لعب موقعهـا الجغر افي دوره في جلب هذه الأفكار والمعتقدات الخر افية من المجتمعـات الأريـة وبـلاد

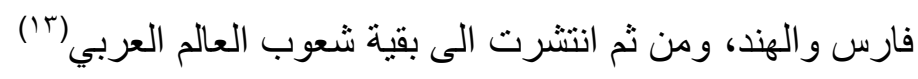

أن طروحسات الفنـانين بهـذا الاتجـاه تتضـمن الأشـكال والمفـردات وعلاقـة البيئة بـالمجتمع اذ نجــ

العناصر الفنية الأخرى مكونةً نظاماً يدخل ضمن نسق عام متمثل في خصائص الفن الثـعبي في انتاج اعمالا تقترب من الحداثة والمعاصرة ، فأعاده بلورة الأشكال و انتاج اعملا فنية دالة على وقائع واحداث من مجتمعها الخـاص، وينبغـي للنتاجـات أن تلامس في الأقل وجهـة نظر الثقافـة المجتمعيـة ومـأخوذة مـن ذاكرة شـعبية

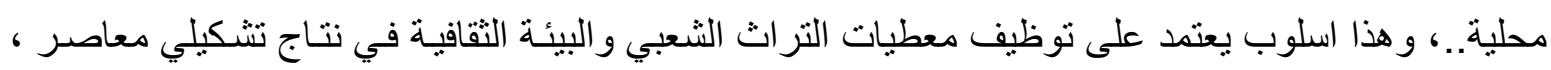
من خـلال المز اوجـة من المعطيات التراثيـة الثـعبية و النص التشكيلي الحديث، وتشكل الخصـائص و السمات الجمالية و الدلالية للمفردات الشعبية باتجاه تعبيري يقترب من التجريد فكانت معالجتها الفنية تعتمد الاختزال و التبسيط او الواقعية و المحاكاة .

ومن خلال ما تقدم نجد أبرز عنصر في تعريف البيئة الثقافة تنتج من خـلال سمات المجتمع بوصفه

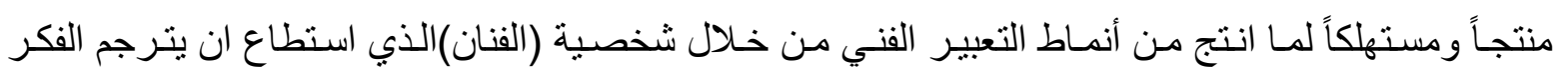

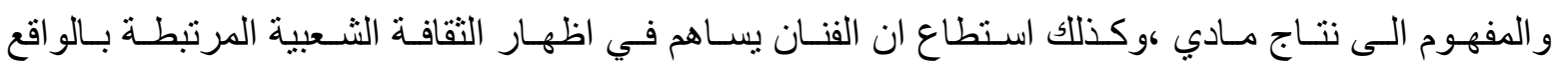
الموضوعي للمجتمع ويعبر عن فكرة او حدث او ظاهرة مما قيل وكتب من القصة، الحدوتة، و الامثنال الثـعبية و القصة الخر افية و الشعر الشعبي وغير ها. المبحث الثاني- البيئة الثقافية والية التوظيف في فن الخزف العراقي المعاصر: يرتبط مفهوم التوظيف بالجو انب الادائيـة والحرفيـة والمهنية، على الرغم من ان هذا المفهوم يحتـاج قدرة عالية على تحليل الفكر الانسـاني وتتكيل الطبيعة البيئة المحيطة كركيزة أساسية تتيح الفرصـة و المجـال

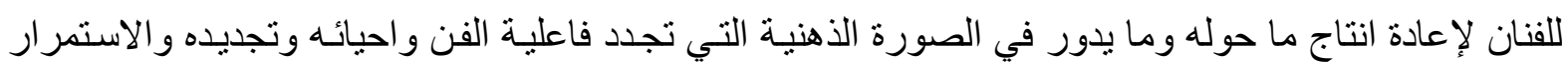

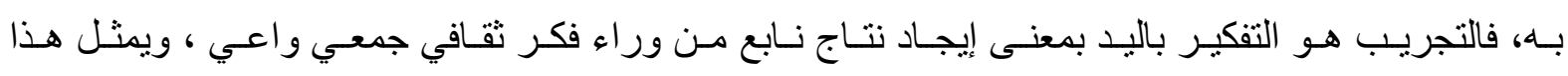

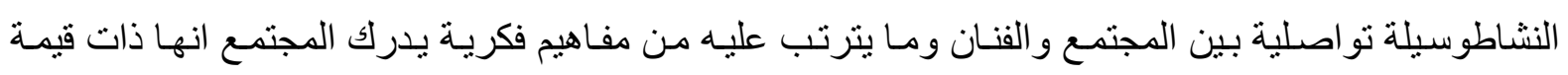
تداولية..اذا فالعلاقات الاجتماعية الثقافية والاقتصادية والسياسية تشكل في حد ذاتها خبرة معرفي في خصوصية الرؤية الفنية الواعية للفنان ذاته وتكون الملاحظة الدقيقة والرصد الحاذق من قبل الفنان لمتغير ات الظواهيه اهر فإنها

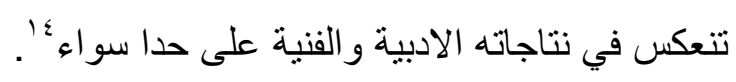

و عليه فان الوظيفة في الفن وخصوصـا فن الخزف لم تنفصل ولم تبتعد بـل كانت الاسـاس الذي شـل المنجز الفني منذ العصور القديمة في فنون وادي الرافدين، على الرغم من اختلاف الوظائف مـا بين جمالي صرف واجتماعي او ديني او نفعي وعلى اختلاف مستوياتها واستخداماتها التي سـاهمت بشكل كبير في اغناء التجربة الفنية في حدودها هذا الفن.. داخل النسيج الاجتماعي الر افديني ان الخزف كنتاج انسـاني ارتبط بوظيفية 
الاداء و الجمـال في آن واحد لكنه مـا لبثت تدريجياً ان ينفصل عن الوظيفـة لصـالح الفن و الجمـال ، وهذا مـا التمسناه في الكثير من الانجازات الفنية التي ظهرت في اتجاهات الحداثة وما بعد الحداثة , فقد ظل فن الخزف وماز ال نقطة اتصـال بين الانسـان وبيئته، بوصفه فناً تجـاوز حدوده كوظيفة استعمالية او اداتيـة فقد انعكس نتاجه على ثقافة المجتمع من خلال جملة من الاشكال التي اتخذت مكانة مهـة في الفكر الانساني ،فمن

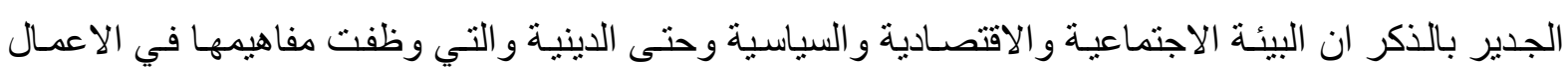

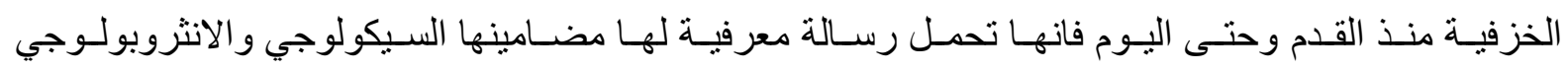
و الفينومينولوجي و المثيولوجي بفعل الحدث او الاستر اتيجيات الضاغطة على الفنان.. فكل منجز فني هو منجز ثقافة يحكي قصة حوارية تروي لنا منـابع المعرفة الانسانية ، لذلك فالأسـاليب متنو عة وكذللك الاداء و الاخر اج من حيث الثكل و اللون و الحجم والخامـة ونوع الزجاج ..الخ ،و عليه تكون النتاجـات الفنيـة الخزفيـة هي ثقافة

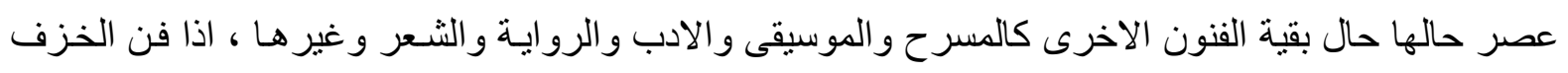

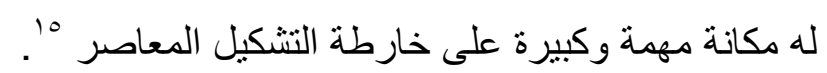
هنا نستطيع القول بان الوظيفة ترتبط بفن الخزف عموماً على اختلاف مسمياتها وتصنيفاتها فمنها مـا يكون مرتبط بمحاكاة الطبيعة الثقافية والاحكام المتو ارثة من جيل الى جيل ومنها مـا بتعلق بــالعادات و التقاليد

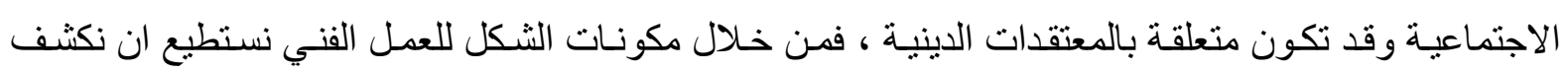
ونحلل خصائص كل عمل وما يرتقي اليه الفكر الذي انتج منـه ،اذ يرى المفكر الانكليزي (ريتشـارد هوكر) ان ان

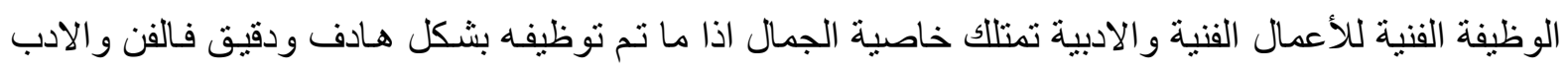
هي رسالة انسانية تكون فيها أهداف خاصـة او عامـة فتؤدي هذه النتاجـات وظيفة معينـة و عادتا مـا تكون هذه

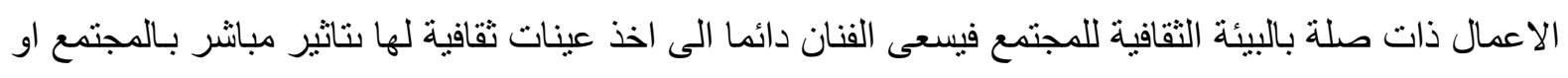

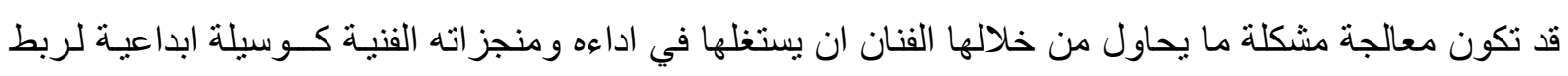
العلاقات بين الأشياء المحيطة باعمال ذات طابع اكاديمي متقن, مشيراً إلى ثقافة المجتمع و علاقتها بـالفن كاداة تفاعلية مرتبط بالبيئة الانسانية(17).

ان طبيعة الفنان العر اقي و علاقته بالبيئة و المجتمع باتت من الأساليب التي تقوم على مفاهيم ومسميات مختلفة فقد ظهرت فنون ونتاجـات تتـارجح بين فكر الانسـان وبيئته الثقافيـة ، وبطبيعة الحسال تكون تأثنير اتها مباثـرة في الاعمـال الفنيـة وهي تحمـل عمـق المفـاهيم الاجتماعيـة الر افدينية كونهـا تعد العمدود الفقري للفنـان وخصوصا اذا ما وظفت الاسلوبية ذات طابع غر ائبي يشمل في ذلك كسر التوقع ويحمل في طياته هـاجس قلق وتعجب بالنسبة اللى الجمهور المتلقي ، لان الأداء و الحرفة والمهارة هي جزء اساسي في تنفيذ نتاجـات ابداعية

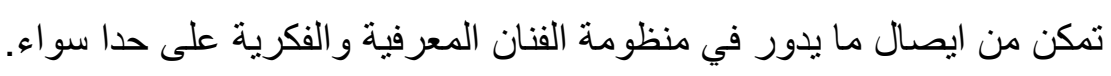
من الجدير بالذكر ان النتاجات الفنيـة الخزفيـة التي دخلت مضمار البيئة الثقافيـة للمجتمع والتي حساول الفنان العر اقي ايجاد ثقافة جديدة واسلوب جديد ومتفرد خاص لكل فنان ، فضلا عن تأثنير الثقافة الخارجية التي

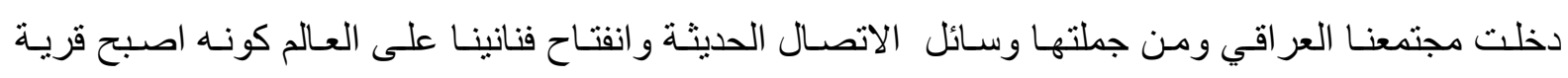


صغيرة ممـا ادى ذلك الى احداث نوع من التبادل المعرفي و الفكري والاجتمـاعي ، فـان تطور المجتمع ادى بالنتيجة الى تطور الفن ، مـا هو الا تطور عنصر نقافي بين عناصر لاخرى كالعلم والادب والفن والتنظيم

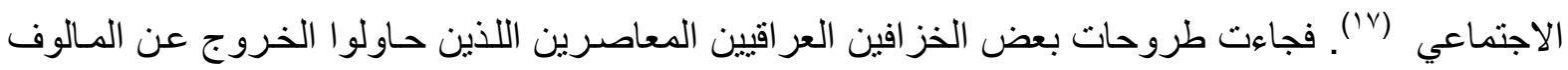
السى نتـاج ابـاعي جديد ومعاصـر متـأثرة بحضـارتهم وتقاليدهم الاجتماعيـة التـي تحمـل ثيمةالروحيـة العر اقيـة الاصلية المتجذرة في تلك الاعمـال كذلك ظهرت اعمـالهم بتكرة بروحيـة تراثيـة محليـة مستوحاة مـن البيئة الاجتماعية.

و عليه ان اغلب الأعمال يتم توثيقها من مفردات بيئية (اجتماعية تاريخية سياسية ) تكون قد شغلت فكر

الفنان واخذت من صورته الذهنية منطلقا في اتجاه الفن .. لان اليـة توظيف البيئة المحيطة في الفن تعد عمليـة تفاعلية قادر ا على الافصاح عن ذاتية وادر الك الفكري و الادائي للفنان .. بوصفها مفاهيم راسخة في مخيلة الفنان فالبيئة المحيطة تشكل نقطة ارتقاء من أجل التوصل إلى موضو عية الفن ذاته,حيث أنها قد تأثرت ببعض التهآراء

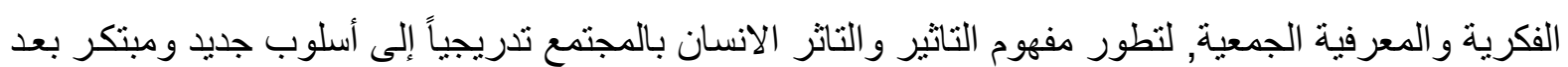

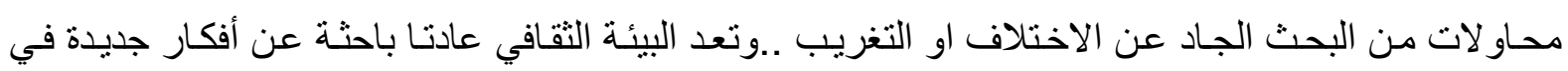
نتاجات الفنان التشكيلي لتتحدى وتبتكر من مرجعيات فنون سبقتها، وأسـاليب مشتقة من رحم الحياة والمجتمع

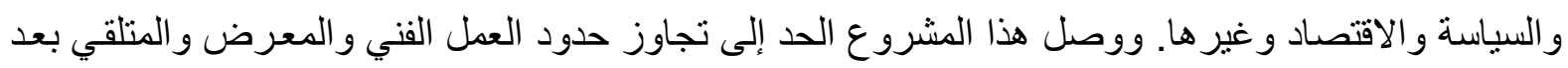

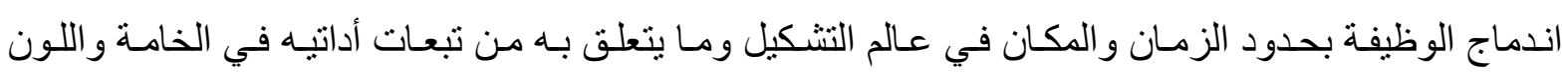

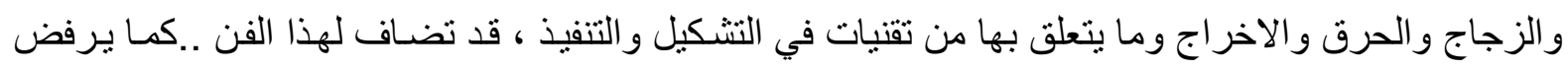
فن الخزف اليوم الخضوع لعمل واحد وهدف واحد ليصف أسلوباً جديداً كون المهارة الفنية التي تبحث في وني العلاقة بين مجموعة من العناصر وتفعيلها بين الأشياء بسياق مستحدث يشمل العرض و الجمهور ، اذ يرى

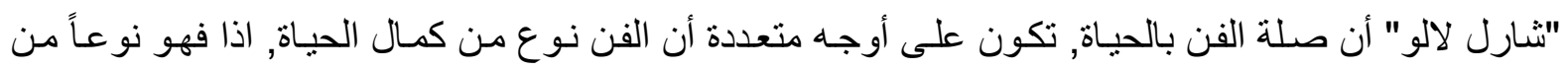
الترف وسط الحياة الجادة المكتئبة, كما أنه يقوم بمهمة تطهير النفس بوصف العمل الفني ذو تاثثير نفسي على

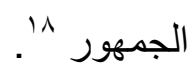

فقد تعددت النتاجات الفنية في مجال فن الخزف والية توظيف البيئة الثقافية العر اقية ، فالامثلة لا حدود لها ابتداءا من الفنان القبرصي ( فالنتينوسكار الامبوس) كونه يعد المؤسس الاول لفن الخزف في العراق حيث كانت البيئة الر افينية من اهم التاثير ات المباثرة التي كانت و اضحة في اعمالـه ومنجز اته الخزفية وكمـا مبينة في الثكل (0 - 7) فقد ارتبطت اعماله بمفردات كانت على صلة بالبيئة التراثيـة الاصيلة والتي كانت مرسخة في الصورة الذهنية للخز اف ( فالنتينوسكار الامبوس ) فقد حقق الفنان تجربـة اتسمت بالمحاكاة و التقليد بالبيئة الحضارية الر افدينية ، مما أعطى هذا الفن مفاتيح التعبير باساليب مختلفة فمن خلال التجريب المستمر في الفكر و التطبيق, باتت هنـاك علامـات فنيـة مميزة تميز هذا الخز اف العـالمي , بسمات فنية وجمالية لم تكن من قبل وظلت مستمرة حتى مغادرته العر اق ، فقد كان تاثير البيئة الاجتماعية والثقافية مباثرة في الكثير من اعمال 
الفنـانين العـر اقيين امثـال (سـعد شـاكر ، طـارق ابـر اهيم ، سـهام السـعودي، شـنيار عبــ الله، مـاهر السـامر ائي

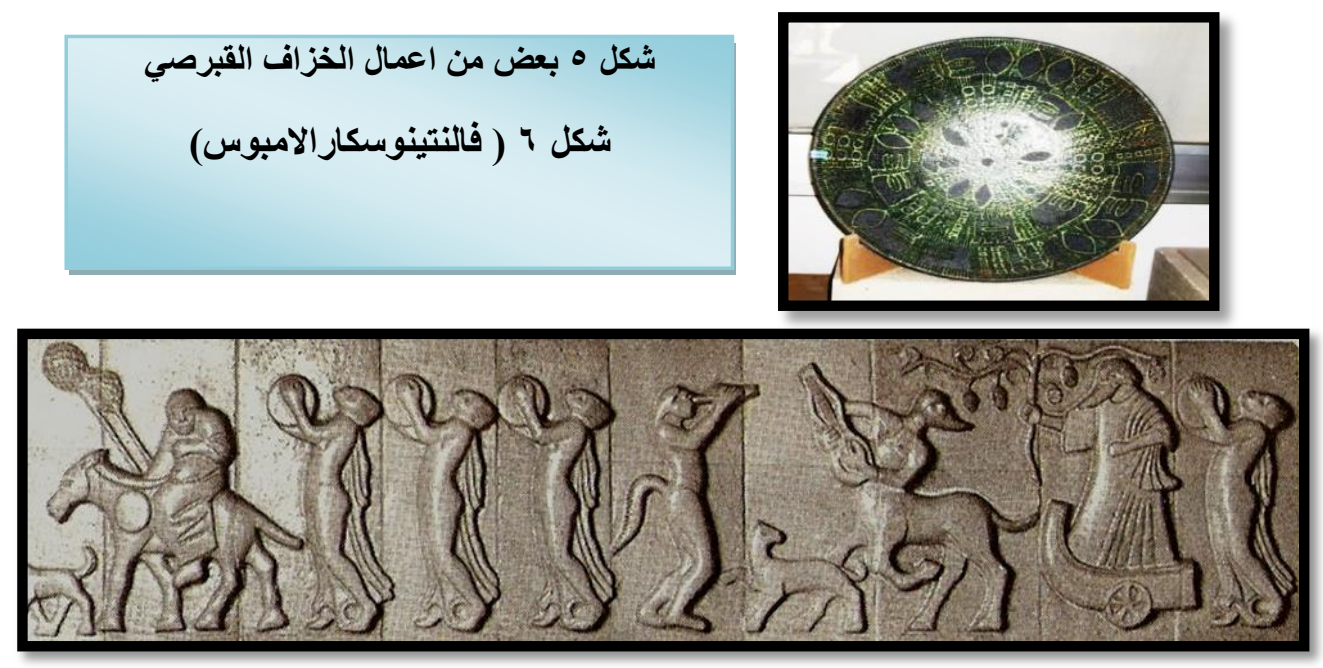

و غير هم)

كونهــــــــا ذات تـاثير كبيــر

علـــى بنيـــة

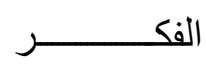

المعرفي لدى

الفنـان العر اقي بصـورة عامـة ، لـللك فالبيئة الثقافيـة لا تتفصل عن الرؤيـة المعرفيـة و الادر اكيـة للفنـان كمبـأ محاكاة العالم الخارجي و هذا يعتمد عليه ما حققه الخز اف العر اقي من وظيفة نفعية جمالية ابداعية تفاعلها بالبيئة المحيطة جعلت هذا الفن يتسم بثنائية مسابين الجمالية والاداتية وان كان في كثير من الحقب السابقة يأخذ ابعاد رمزية أو عقائدية دينية وما الى ذلك. مما تطلب من الخزاف فاعلية اكبر لاظهار سمات وخصـائص فنية جديدة

تعتمد على المحاكاة للو اقع الاجتماعي وما ينعكس من خلال التحولات السياسية و الاقتصادية والاجتماعية . كما يرتبط مفهوم البيئة الثقافية لدى الخز اف الفنان ارتباطاً مباثـراً مـع الخامـات واليات العمل والتنفيذ بتقنيات تتلائم مع نوع الطرح وكذلك بما يخدم كلية العمل ، و هنا تتصب علاقة جدلية في تأليف الأسلوب الفني للفنان ويأتي ذلك ضمن اختلاف الرؤى والميول و الوعي بين فنان وآخر تؤدي الى ايجـاد المنـاخ المناسب للفنان وتحقيق اسلوبه الفني الخاص اذ نظهر علاقة العناصر الثكلية بعضهـا مع بعض في كثف قصدية الفنان لمـا يشير اليه في تحديد بنية الموضوع تداخلها وتفاعلها امـا بشكل بسيط يسهل قر اعتها او بشكل معقد ( شفرات ) يصعب الافصاح عنها و هذه من أهم سمات العمل الفني الابداعي لكل فنان ، لأن العمل الفني هو شكل معبر عن بن

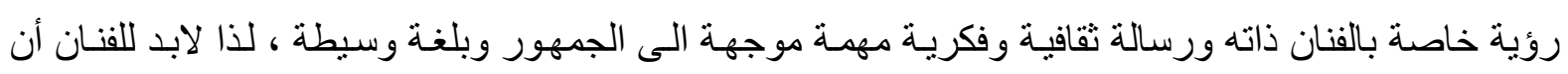
يكون متفهماً وحذر لتلاك اللغة, حتى يمكن أن يعبر بها من خلال أشكاله التي يبتكر هـا من وحي افكاره ووخيلته الذهنية ، و عن طريق تنظيمه للخصائص التشكيلية والتعبيرية من خلال ( الخامة ) التي يتخذها وسيطاً لأشكاله. ومن ضرورية أن يضع في إعتباره مـا إذا كان قد تم إستكثـاف جميع الإمكانيات والتقنيات المختلفة للوسـائط

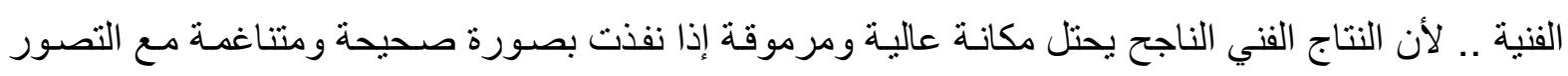
العقلي و المعرفي ليحقق انسجام بينه وبين رؤية الجمهور النخبوي ، لذلك يجب مر اعاة المفردات والعناصر التي

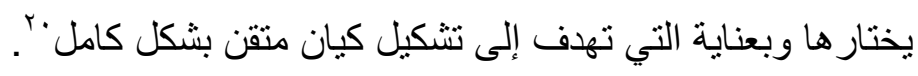

و إذا كانت وحدة العمل الفني تقاس بمدى أهمية ثقافة المجتمع في إطـار كلي, بحيث تكون بينة كاملـة ومنغلقة على ذاتها ، وأن كلية العمل الفني تفقد وحدتها في حالة حذف جزء أو إضـافة جزء آخر، فـإن تلك

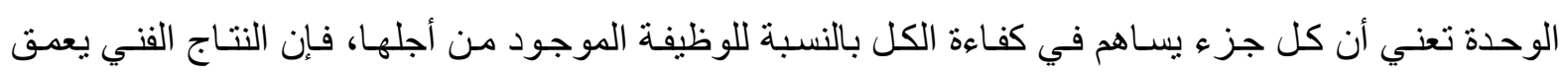


بصيرة المتذوق, لربطها بدلالة منشئها وبيئتها التقافية ، سواء كانت طبيعيـة أو صناعية او علمية , على النحو

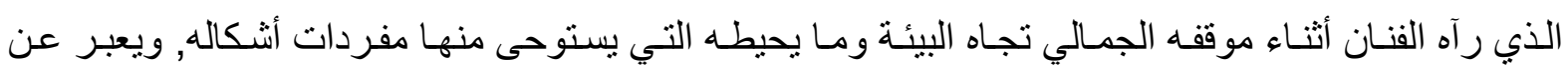

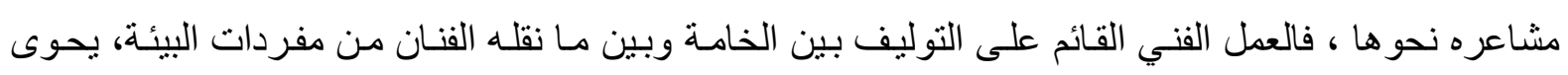

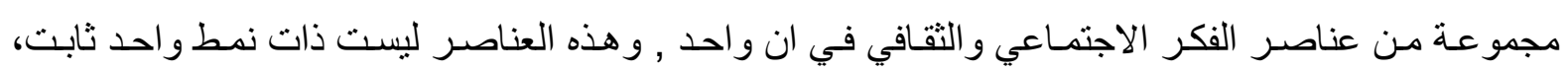

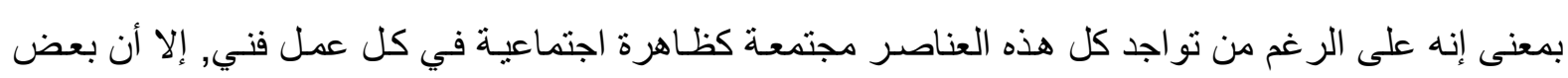

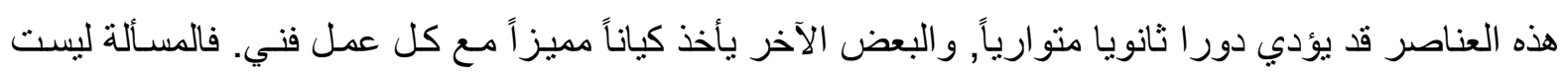

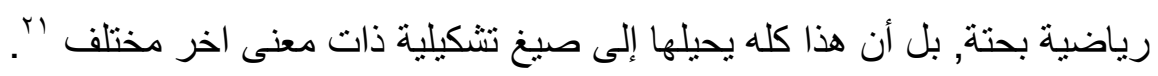
و عليه وبناء على ما تقدم يتبين للباحث إن ناثير البيئة الثقافية هو محاكاة للواقع الاجتماعي و الاقتصسادي و السياسي باستخدام مفردات مستوحاة من عمق الارث الحضـاري ويعتمد مرجعياتها حيث الانتمـاء التاريخي و الجغر افي و هذا ما يفتح حوار ديالكتيكي جدلي ممتد من العصور القديمة وصـولا إلى عصر الحداثة ومـا بعد بـد الحداثة ، بحثا عن اشكاليات بصرية متحولة بين الو اقعية والتجريدية على وفق مـا تقتضيه شروط البيئة الثقافيـة و الية توظيفها في فن الخزف ويكتسب مرجعياته من الواقع المـادي لكن عناصره تفتقد خصوصياتها الأوليـةن ونس تصوير وتتكيل و اداء واخر اج ، و التي تعطي ثراء في المعنى و التأويل ، أو توضيح مفهوم عن قضية او مشكلة

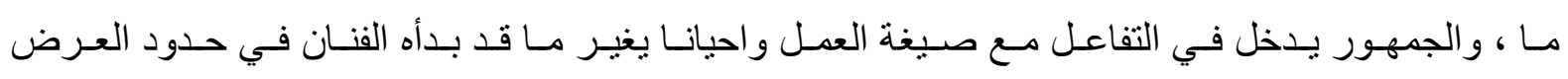
و الاستعر اض اذا هذا يتطلب تدريب حاسة البصر على التأمل و النظر وملاحظة البنيـة العمبقة في البيئة الثقافيـة للمجتمع فضلا عن التأمل الحاذق الذي يأتي بالنظر إلى الأشياء مع ملاحظة شيء يكون متخفي خلف الاشياء ،

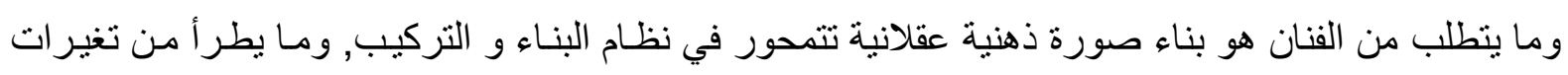
على عناصر الثكل اللون الحجم والحركة والخامة وايجاد علاقة هرمونية تشكيلية ينم إدر اكها وتو ازنها في بنـاء نتاج فني معين.

ومن خلال ما تقدم يتبين لنا ايضـا ان البعد الجمالي للبيئة الثقافيـة هي لغـة خطابيـة بمضمونها الاجتمـاعي التي حقق فيها الفن موضوعيته و اصـالته داخل بنيـة المجتمع على ان يكون ذلك مصساحبا للتجديد الذي اصبح ضرورة اجتماعية ، بمعنى كلمـا ازداد الوعي الجمـاهيري ازداد الخيـال للمجتمع واصبحت افق القراءة الثقافيـة و المعرفية مصاحبة للغر ائبية والصدمة في التعبير الفني والاداء و الحرفة الذي لامسه المجتمع من قبل الفنان في

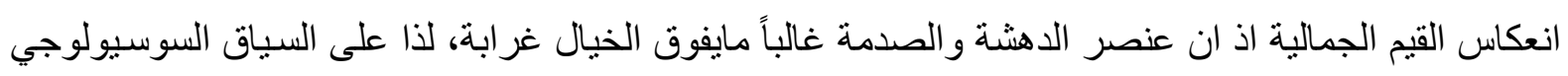
ان يكسر السياق و النسق المتعارف علية ويؤكد مصداقيته ومضمونه للبيئة الثقافية

\section{هؤشرات الاطار النظري :}

م ان من اهم المؤشرات التي تدور حول طبيعة البيئة الانسانية تجاه الفن هي (المعتقدات الدينية) بوصفها

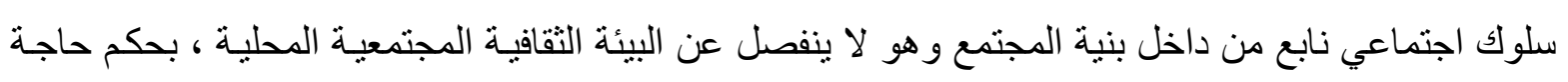
المجتمع الى من يقود افكاره ومفاهيمه وتوجهاته الحياتية وامور تدابير حل مشكلاته الدينيـة والدنيويـة ، وصسار

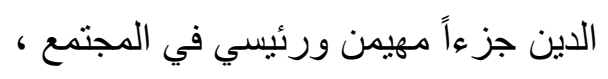




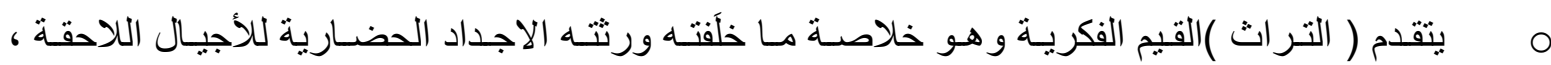
فالتراث يعد منهجا حضاريا و أبستمولوجيا في نقافة المجتمع ،وتثكل بمجملها الجوهر الروحي لهويـة المجتمع (الهوية الحضارية) و هذا الإطار الذي يشكل المحرك الرئيسي للصورة المهيمن للمجتمع ،ومن خلالها يتفاعل معها الفنان.

م يرتكز ( التراث الثعبي )الفلكلور على فكر المجتمع ومايتعلق بمجموعة بشرية ترتبط بعناصر ثقافيـة تستند على الأدب و الفنون وتعبير عن تجاربها وفعالياتها ضمن دائرة التقاليد والأعر اف الاجتماعية ، و هذه التقاليد

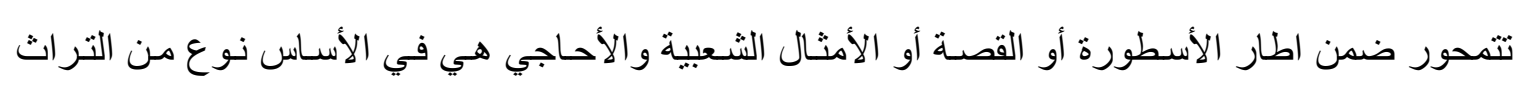
الثعبي أو ( الفلكلور ) أو ( المأثورات الثعبية ) .

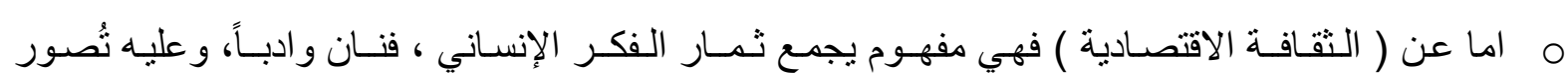
البيئة الاقتصادية كمنهج لفهم كيفية تكيف الإنسان للحياة الواقعية بما يتلاءم مع حاجات الانسـان ومتطلباته ، وفتح افاق التطور التي تغير الثقافة من خلال سمات (المجتمع) وهذا يؤدي إلى تطوير منهج تصرفات

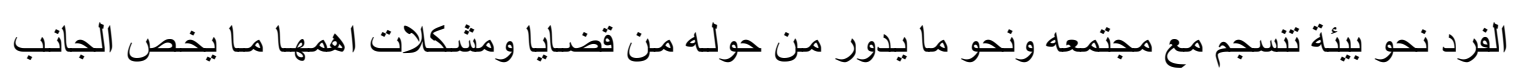
الاقتصادي، وهذه النظرة لها موقفان أولهما الموقف الذي يقر بموجبه من الوجود المـادي الو اقعي ويميزه

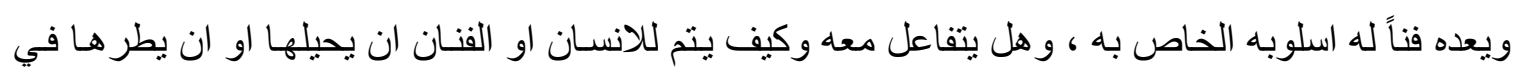

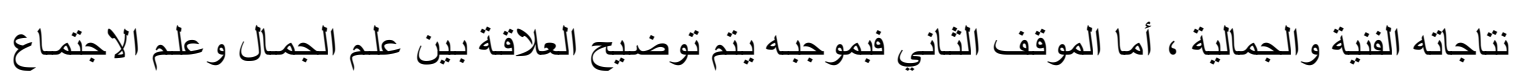
و الفلسفة قبل كل شيء إدخال سمات الترا وتفاعله في النتاج الفني .

اجراءات البحث

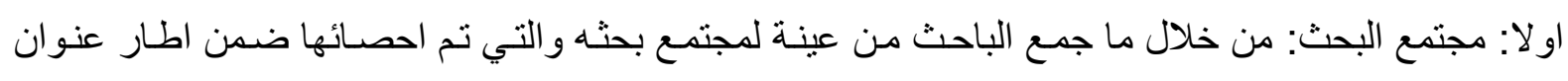
البحث الموسوم (البيئة الثقافية واثر ها على الخزف العر اقي المعاصر) ، وضمن الحدود الزمانيـة للفترة المحددة

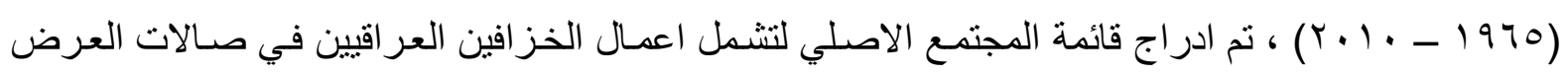
الفنية داخل وخارج العر اق فضلا عن الكتب و المجلات الفنية و الاستعانة بشبكة الانترنت ، وبمـا يتلاءم وهدف البحث ، تم احصاء (190) عملا خزفيا ، نم ادر اجها على وفق الجدول الاتي:

\begin{tabular}{|c|c|c|c|}
\hline عدد الاعمال & اسم الفنان & عدد الاعمال & اسم الفنان \\
\hline 9 & كاظم غانم & 88 & سعد شاكر \\
\hline 125 & اكرم ناجي & 25 & محمد العريبي \\
\hline 15 & ثامر الخفاجي & 39 & طارق ابراهيم \\
\hline 266 & ماهر السامرائي & 74 & شنيار عبد الله \\
\hline 29 & سلام جميل & 86 & قاسم نايف \\
\hline 24 & عبلة الغزاوي & 44 & سهام السعودي \\
\hline 37 & احمد علاوي & 34 & تركي حسين \\
\hline & & & \\
\hline
\end{tabular}


ثانيا: عينة البحث: حدثت عينة البحث من خـلال اختيـار ( العينة القصدية ) ، وبمـا يتلاعم هدف البحث ، اذ تم انتخاب عدد من الأعمال الخزفية على وفق ما تم تحديده ضمن مؤشرات الاطـار النظري و التي سيلجأ الباحث

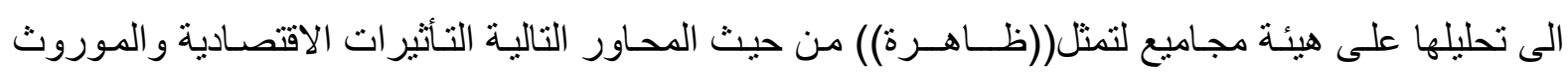
الحضـاري والتي حددت محددات التحليل كاثر بيئي وثقافي من الظواهر التي اخذت حيز ا كبير ا في فلسفة

$$
\text { الخزف المعاصر العراقي . }
$$

ثالثا: منهج البحث: اعتمد الباحث المنهج الوصفي التحليلي كمنهج لتحليل عينة البحث الحالي .

رابعا : تحليل العينة:

المجموعـة الاولى :وتشـمل هذه المجموعـة الاعمـال الخزفيـة تعكس الحيـاة الاقتصـادية بمـا يتلاءم مـع حاجـات الانسان ومتطلباته كظاهرة مهمة ومحفزة للسوك الانساني الجمعي .
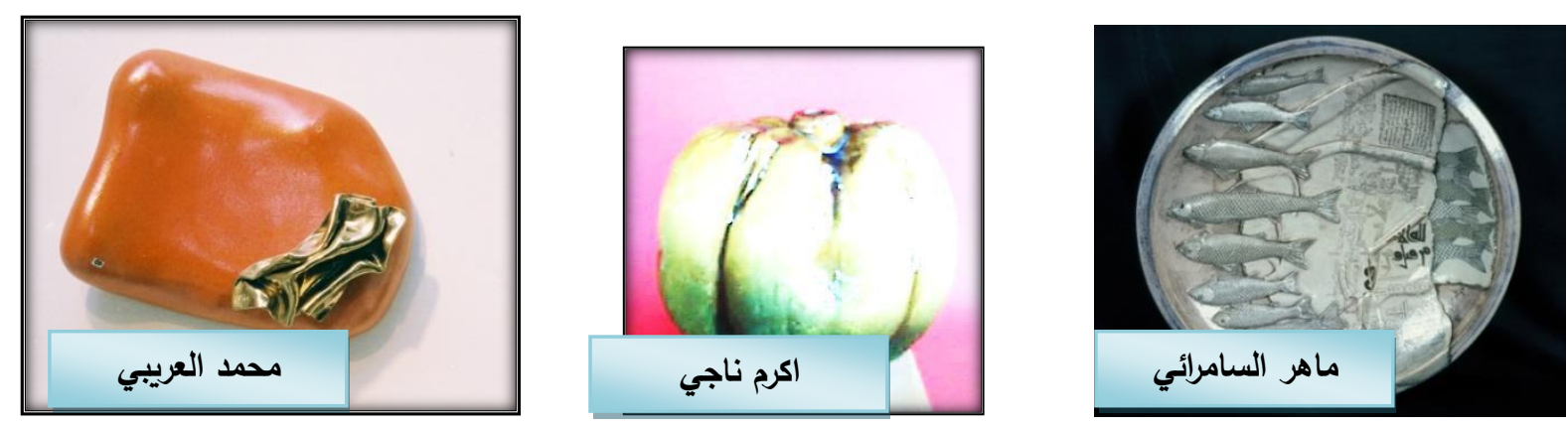

تشكل البيئة الاقتصادية خطابا لا يخلو من الواقعية وبما يعكس الارتباط المباشر بمفاهيم الفكر الانسـي وهذا مـا يتيح للفنان ان ينفرد بخطـاب الجمال و الابداع متنـاو لا بذلك حريـة التعبير من خـلال تفاعل الانسـان مـع البيئة الاقتصادية وبما ينسجم لبناء علاقة مشاركة بين الفنان وبيئته موضحا بذلك هوية الاستهلاك الاقتصادي بوصفها العنصر المهيمن على العالم المعاصر ،لقد كانت خطابات الخزافين العر اقيين واضحة فظهرت الاشكال وهي تقترب من الطبيعـة بفعل الو اقع الاستعمالي والوظيفي للمـادة الاستهلاكية للمجتمع بوجـه خـاص ، وان اهتمـام

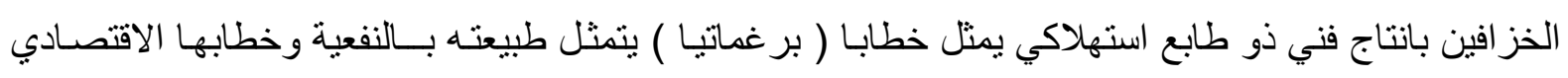
مع ثقافة جو هر المجتمع.. اذ هي محاولة الجمع بين خطـاب العودة للطبيعة والخطاب النفعي الاقتصـادي ،فلم يتحقق الاستغناء كليا عن المنافع الاقتصادية الكبرى التي تحققت للمجتمعات بشكل عام والمجتمع العر اقي بشكل

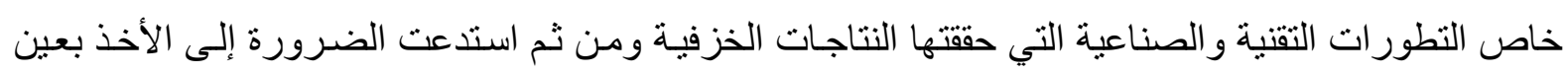
الاعتبار تحقيق الفنان المنفعة الاقتصادية في مفهومه الفكري في صلب الممارسات الفنية المتعلقة بالبيئة الثقافية و الجماليـة الوظيفية ومـا حققته النتاجـات الخزفية التـي شكلت ظـاهرة مهمـة على صعيد الثقافة الاقتصـادية في مجتمعنا المحلي ، و عليهـ فـان الدعوة لانتـاج اعمالا فنيـة خزفية تتطلب من الخزاف دراسـة البيئة التقافيـة ومـا تقتضيه الحالة الاقتصادية والتي تاتي منز امنة مع متطلبات نجاح العمل الفني ، وبدا عملية التفاعل بين العمل

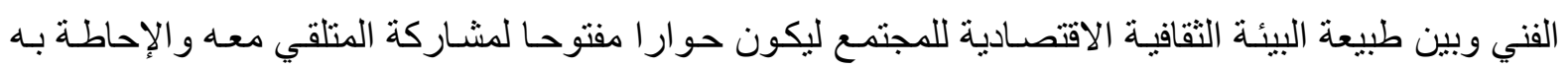


المجموعة الثانية : :وتثمل هذه المجموعة الاعمال الخزفية التي شكلت ظـاهرة ذات صـلة بــالمعتقدات الدينية ، كذلك النتاجات الفنية الخزفية المتعلقة بالهوية الحضارية ، فضلا عن الاعمـال ذات المنحى الفلكلوري الثعبي ، بوصفها ظاهرة اجتماعية مهمة نابعة من داخل بنية المجمع التي تعد احد عناصر البيئة الثقافية العر اقية .

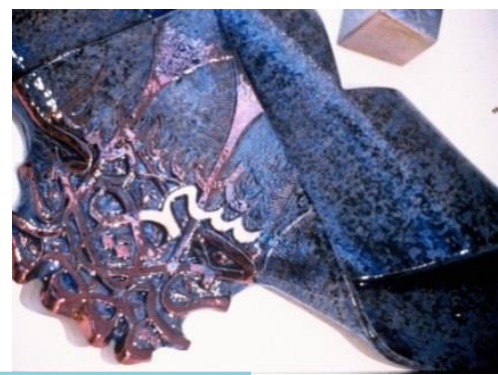

اكرم ناجي

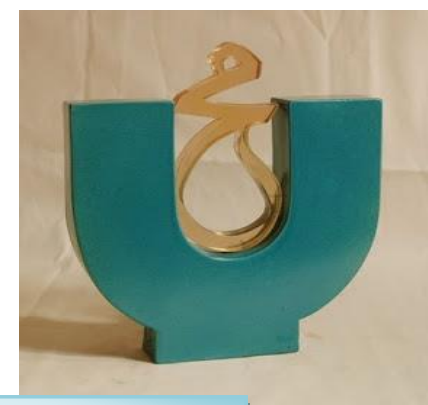

طارق ابراهيم
ماهر السامرائى

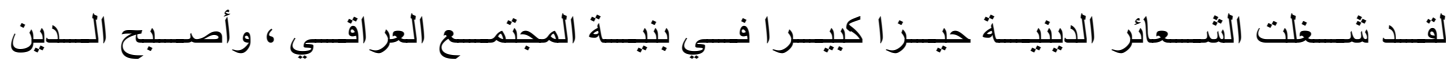
نظامـاً سلوكياً اساسيا يقوم على معتقدات الفكر الاجتمـاعي النابعة من البيئة التاريخية المتجذرة بعمق الارث الحضاري الاسلامي ، فقد برزت ظاهرة الدين في الاعمال الفنية من خلال ( الحرف العربي ) الذي بدا واضحا في الكثير من نتاجات الخز افين العراقيين ، فقد ظهر الحرف مرة بصورة واقعيـة أي بشكل مقروءة وفصيح ، واخرى يظهر فيها الحرف العربـي بهيئة رموز و علامـات مجردة ، معلنـة بـللك عن خطساب حضـاري ومـا للحرف العربي من قيمـة ومنزلـة مهمة شغلت الكثير من فنانينا التشكيليين بشكل عام وفنـانين الخزف بشكل

كما اظهرت هذه المجمو عة التمثلات الاستعارية للارث الحضـاري الر افديني من حيث الثكل واللون و الحركة و غير ها ، وحضور ايقونات البيئة التاريخية و الاسطورية بصيغة معاصرة مبتكرة ، مع مـا هو مـادي او و اقعي منقو لا ايقونيـا الارث الر افديني القديم ، واظهرت التشكيلات الخزفية +بأسلوبية منفتحـة القراءة في تكوينها وبنائيتها و إحالتها الى الدلالية والمرجعية القديمة ، في حين اتخذت المضامين الفكرية و المعرفية ومـا لها ولها مرجع يتجسر مع الفن السومري والاكدي والاشوري كما جاء في النماذج اعلاه من عينـة البحث ، بحيث كانت النتاجات الخزفية مرتبطة بمفاهيم الخصوبة و النماء والقوة و الديمومة والاحتفالات لتقديم القر ابين للإلهـة التي بثت خطابات ثقافية لمدلو لات رمزية مشفرة في الفكر الر افديني في شكلت من نتاجات فنية اخذت حيز الرموز في بنى عميقـة و علاقتها بـالقوى الغيبيـة ودلالات شكلت الرؤيـة الأسطورية الميتافيزيقيـة الغامضـة وطابعها

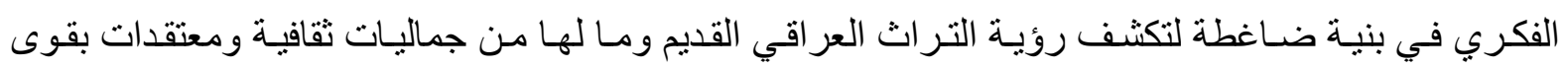
الماور ائية والتي انعكست على النتاج الثقافي والادبي والفني للخز افين .

امـا النتاجـات الخزفيـة المتعلقة بـالموروث الثـعبي العر اقي فهي نابعـة من قيم روحيـة شكلت انعكاسـا للتقاليد الاجتماعية ورؤية تواصلية تخاطب المتلقي من خلال الاحاسيس والمشاعر المنوارثة من جيل الى جيل، بمعنى ان الفلكلور الثـعبي هو ظاهرة لها خصوصية سوسيولوجية اثتنملت على استلهام مفردات البيئة من الو اقع لكنها تتحدث بلغة الحداثة والمعاصرة ، اذا الخز اف العر اقي المعاصـر قدم صورة ذهنية اهتمت بإعادة 
بناء الماضي من جديد ليكثف عن مضمون القدرة في التعبير عن المعنى التي ترمز لها تلك المفردات كـ (الثناشنيل و القوارب و الثـمس والمـاء ) و غير هـا فكل هذه المفردات مقدسة وتحتل مكانـة كبيرة في المجتهع

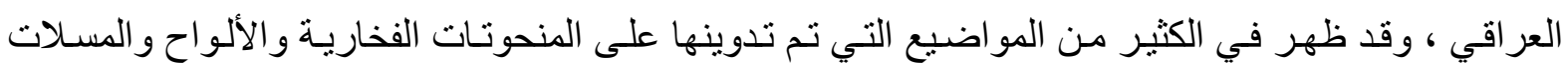
و غير ها التي شكلت ثقافة معرفة اجتماعية في الثقافة العر اقية المعاصرة .

فقد قدم الخز افين العر اقيين المعاصرين نموذجا معرفيا من رحم البيئة الثقافية كتجربة ناتجة من صـراع

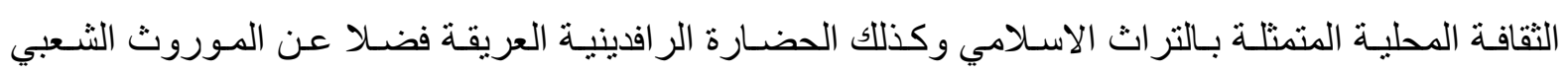
الفلكلوري ، اذ تعد هذه المفاهيم كرمز للحضارة العر اقية المعاصرة ، المستلهمة مفرداتها رحم البيئة العر اقية ، فكانت تقدم انطباع روحي ووجداني، لذلك فان تعامل الفنان مع هذه المفردات الثقافيـة كمـادة لها فعلها الضـاغط و المهيمن في البنية الثقافية والفنية للمجتمع العر اقي المعاصر ، ويتعين على الفنان بأن تكون هذه المفردات أكثر

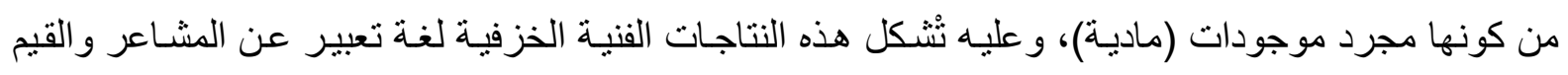
الجماليـة والاجتماعيـة الفلكلوريـة التي تقوم على أنعكاس لهويـة الموروث الحضـاري و الثـعبي، و التـي تحكمـهـ دينامية الانفتاح و الانغلاق حسب رؤية الفنان وثقافته العلمية في ايجـاد ايقونـات مميزة لنتاجهـ الخزفي حسب مـا

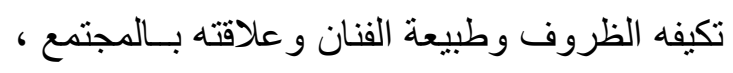
لقد اخذت الحرف العربي والارث الحضـاري و الثـعبي مسـار ا طويلا في بنية الخزف العر اقي القديم و المعاصر وتثير الدلالات الا ان هذه المفردات كانت تظهر وتبرز بشكل مغاير واسلوب جديد يغلب علية طابع الاختز ال و التجريد بحيث كانت قراءته منفتحة التاويل مـن حيث تفسير او تحليل المعنى كمـا مبين اعلاه في وني

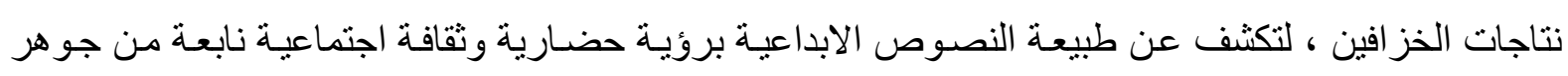

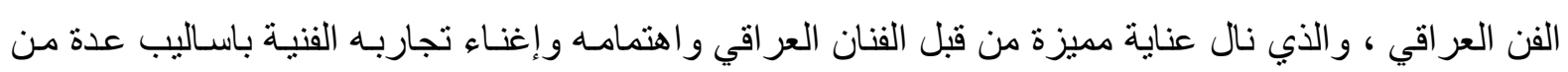

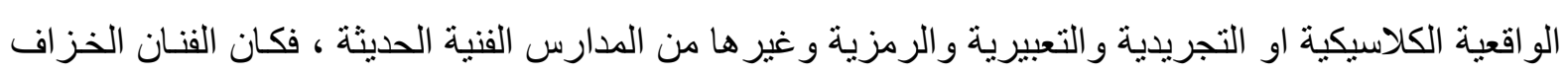
له القدرة على تغيير وتحول خامة الطين البسيطة إلى نتاجات متحرك تحمل دلالات فكرية وجمالية ابداعية .

الفصل الرابع: البع: نتائج البحث

من خلال ما جاء في البحث الحالي في الفصول السابقة ، وما الت اليه مؤشرات الاطــــار النظري ، وتحليل العينـة ، فقد توصل الباحث الى النتائج الاتية :

هـ اظهرت بعض الاعمال الفنية الخزفية ذات ناثير(الحرف العربي) وهي تحمل دلالات ونصوص ( لآيات قر آنية) ،حيث استلهمت من بيئاتها الثقافية جذور التراث الاسلامي، بحيث وظفت هذه ( الآيـات ) باسلوبمعاصرذو رؤيـة

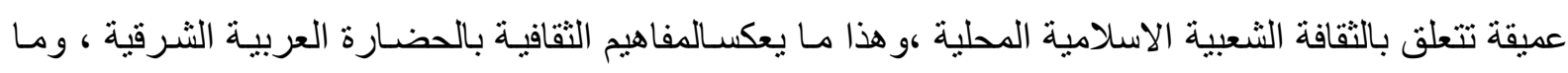

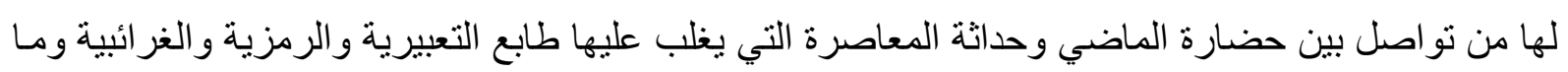
اشارت اليه هذه النتاجات ، انفتاح التاويل وتعدد القراءة في التحليل والتفسير مما يعطي اكثر من معنى في عمل فني واحد . 
ثم اظهرت مجموعة من الاعمال الخزفية والمستمدة من الارث الحضـاري الر افديني القديم ، فثكلت بيئتها الثقافية

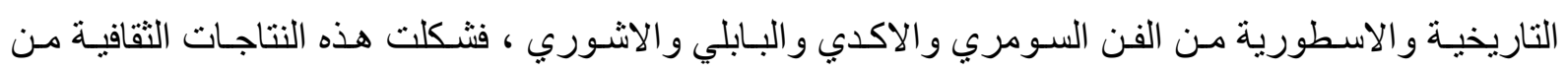

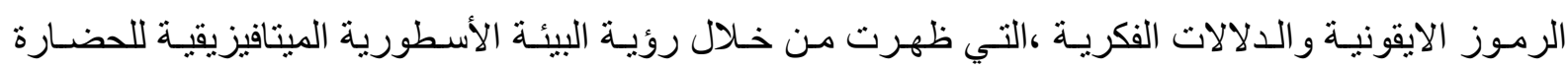
العر اقية القديمة . هـ ظهرت قسم من الاعمال الخزفية ذات تاثير بالبيئة الثقافية المحلية المتمنلة بـالموروث الثعبي (الفلكلوري) النابع من قيم روحية شكلت انعكاسا للتقاليد والاعر اف الاجتماعية ذات رؤية تو اصلية مي الصسورة الذهنية للمتلقي من خلال تداول مفردات الفلكلور الثعبي في صياغة الاعمال الفنية الخزفية بحيث كانت هذه النتاجـات ظـاهرة ثقافيـة مهمة في المجتمع العر اقي ، لما لها من خصوصية سيكولوجية وميثولوجيه اشتملت على استلهام مفردات البيئة الثقافية من الو اقع المادي المحلي فظهرت مفردات الثناثشيل والقباب و الابواب و غير هـا من الالوان ، فقد عبرت عن المثـاعر القيم الجماليـة والاجتماعيـة الفلكلوريـة التـي تقوم على أنعكاس لهويـة المـوروث الثـعبي المحلي العر اقي .

اظهرت نماذج الاعمال الخزفية ذات تاثير بالبيئة الثقافية المتعلقة بالجانب المـادي الاقتصـادي والذي لا

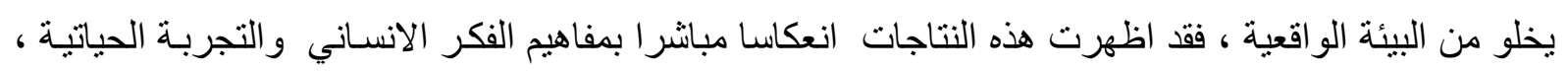

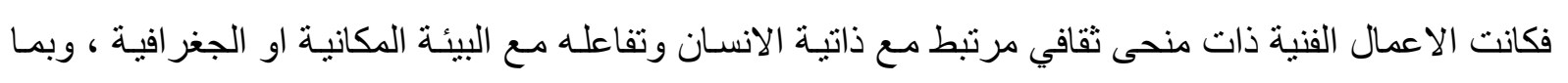

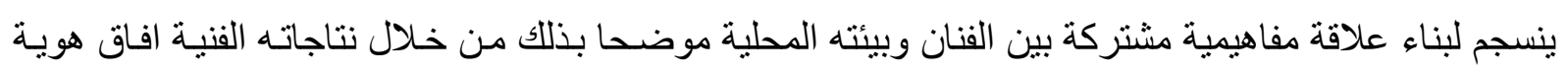
الثقافة الاقتصادية بوصفها العنصر المهيمن في هذا العالم وخصوصـا المعاصر، فقد كانت هذه النتاجـات تفاعلية بين العمل الفني وبين طبيعتها البيئة الثقافية و الاقتصـادية للمجتمع لتكون هذه الاعمـال حوار المفتوحسا لمشـاركة المتلقي معه و الإحاطة به و التفاعل معه .

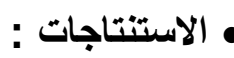

من خلال ما جاء من نتائج البحث الحالي ، يتبين للباحث ان البيئة الثقافية هي مصدر الطاقة للـفن العراقي قديما

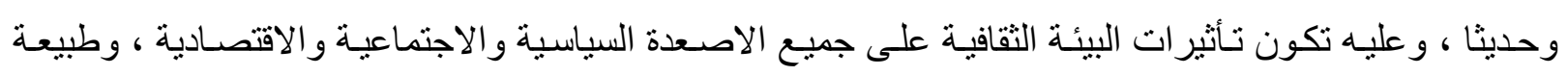

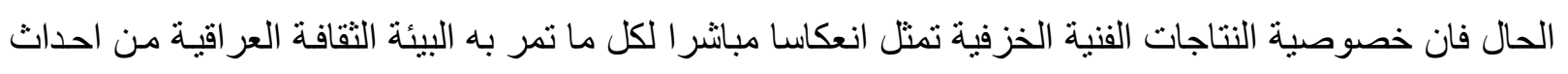
وثورات فكرية ومعرفية.. و عليه فيكون على عاتق الفنان مسؤولية كبيرة في هذا الجانب ، لذلك يجب ان يكون

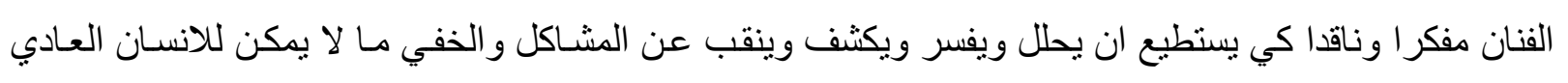
ان يكثفه، وبـللك يستطيع الفنان ان يحاور ويخاطب المجتمع و الجمهور من خـلال نتاجاتـه الفنيـة الخزفيـة بصورة تفاعلية وتواصلية ، بمعنى ان الفنان هو جزء لا يتجز أ من طبيعة المجتمع ومن بيئته الثقافية.

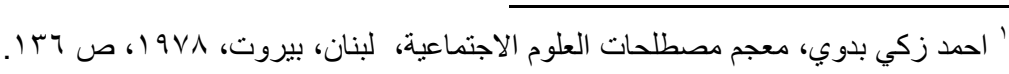

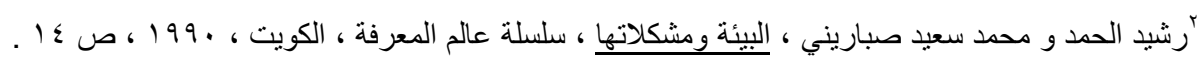

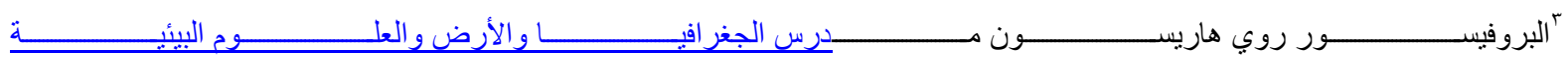
من الملكة البريطانية الثانية برمنغهام .. وهو أحد أثهر علماء البيئة المعروفين عالمياً ويشغل حالياً منصب رئيس اللجنة الإستراتيجية للبيئة 


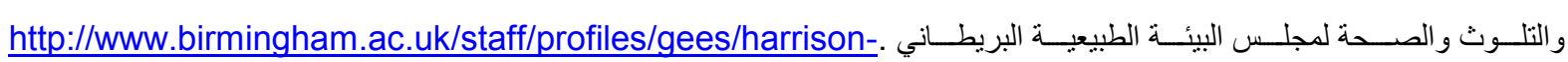

roy.aspx

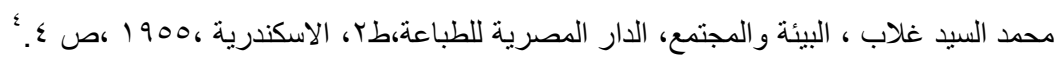

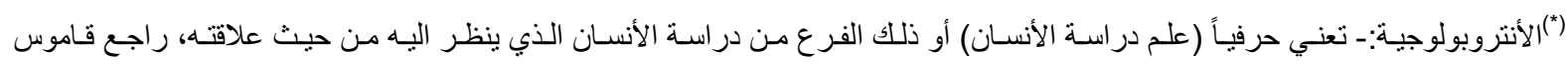

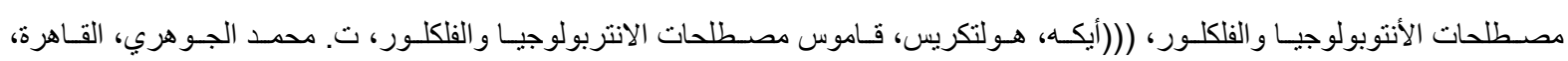
$((() .9 \vee r$

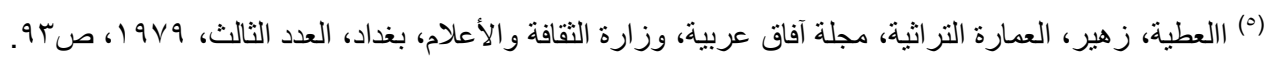

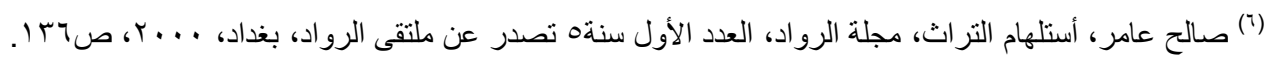

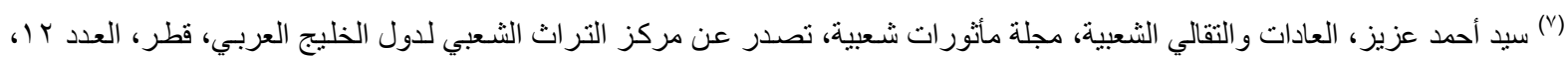

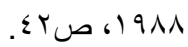

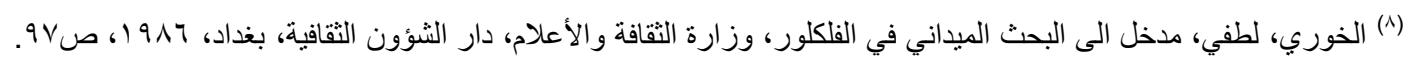

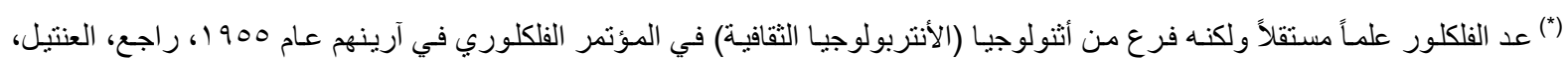

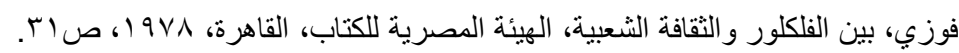

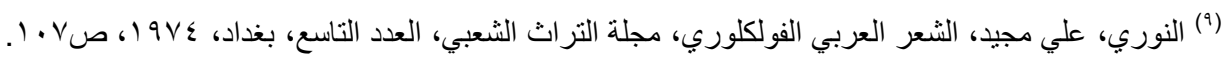

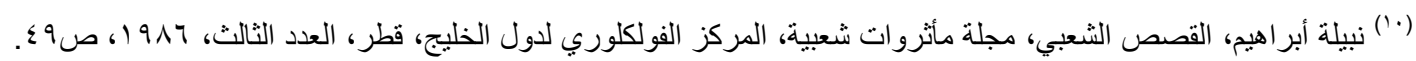

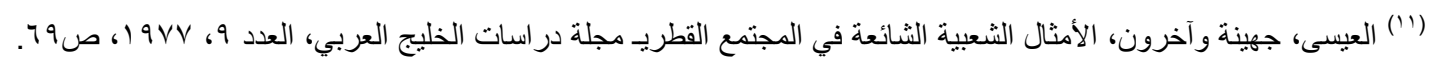

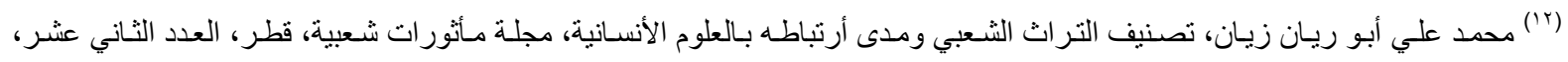

. $\varepsilon r(911$

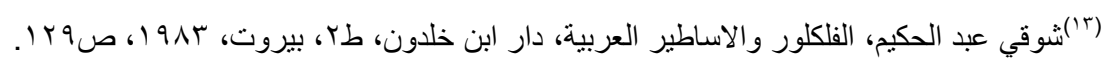

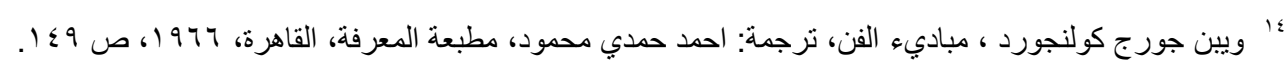

IThames\&Hudson: Dictionary of Art Terms, p)1^-119.

${ }^{(17)}$ Richards Hooker, The Works of that Learned and Judicious, Pinine , mr.Hooker, p. r...

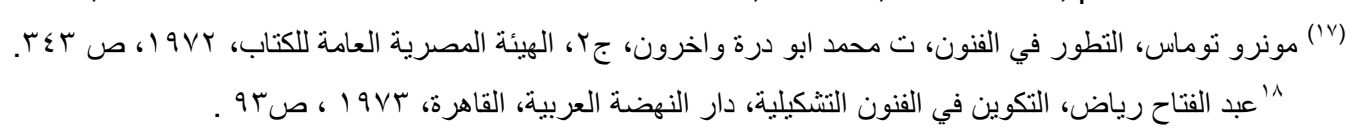

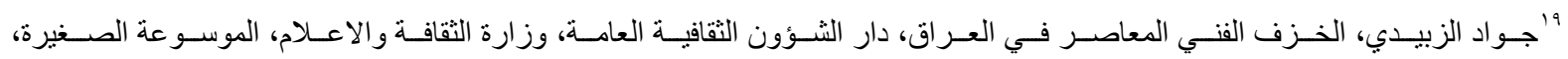

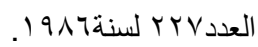

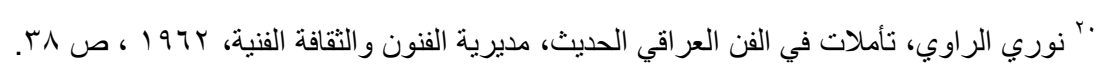

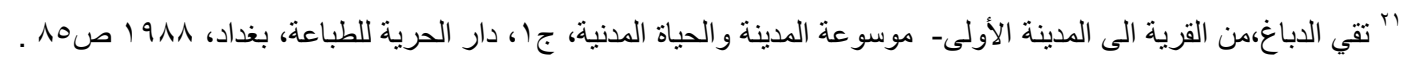

قائمبهة الاصمادر :

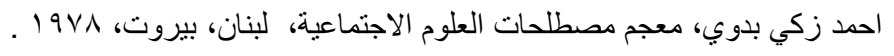

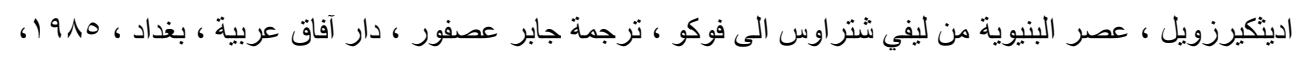

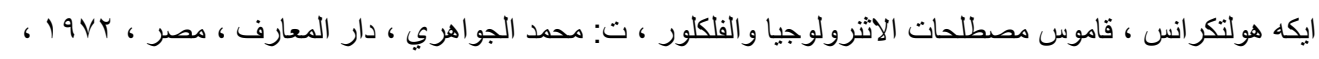

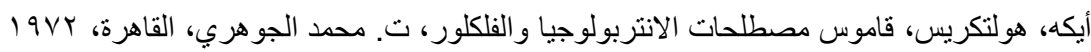

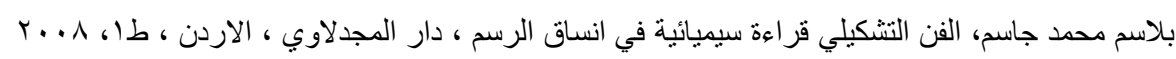

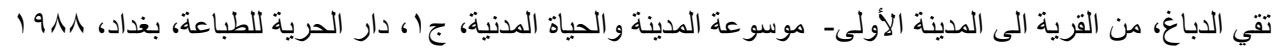

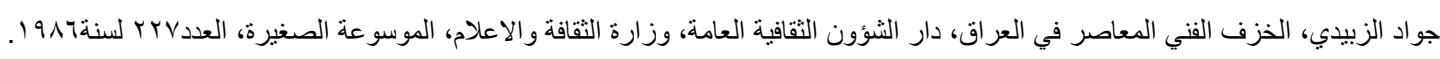

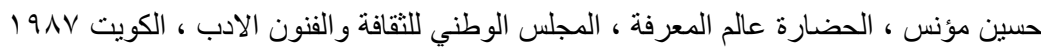

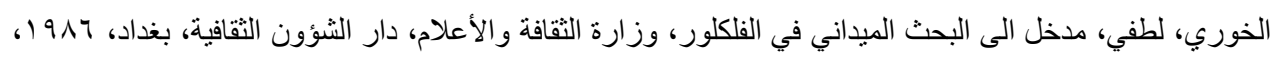


ديفيد انغيلز ، جون هغسون ، سوسيولوجيا الفن طرق للروئة ، ت: ليلى الموسوي ، سلسلة عالم المعرفة ، المجلس الوطني للثقافة والفنون

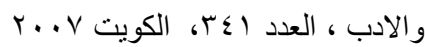

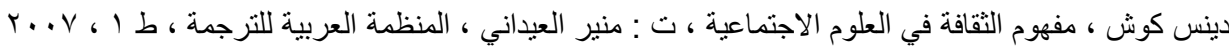

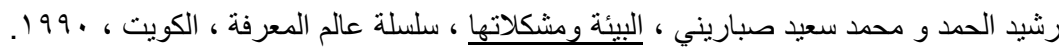

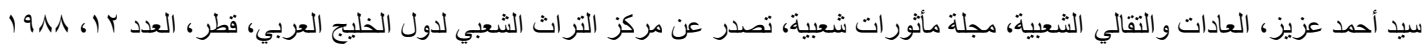

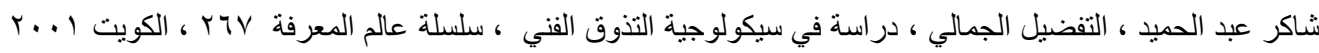

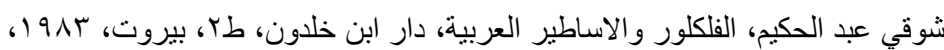

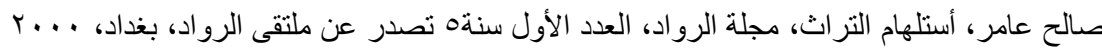

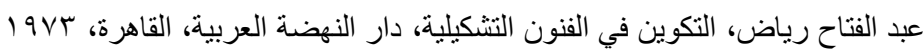

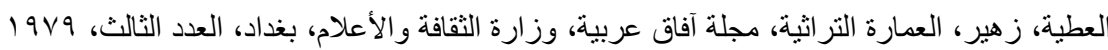

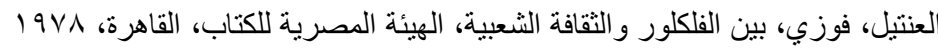

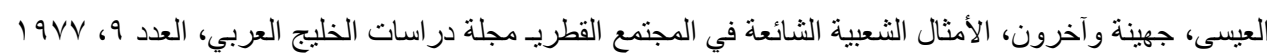

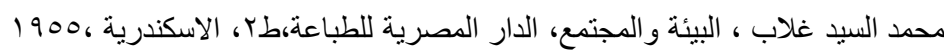
محمد علي أبو ريان زيان، تصنيف التراث الثعبي ومدى أرتباطه بالعلوم الأنسانية، مجلة مأثورات شعبية، قطر ، العدد الثاني عشر، 1911 ، المعجم الفلسفي المعاصر : مجموعة علماء السوفيت، دار التقام، موسكو، ترجمة توفيق سلوك.

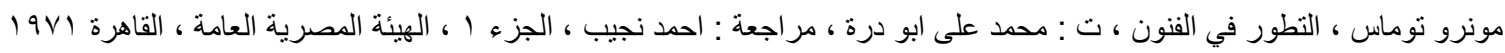

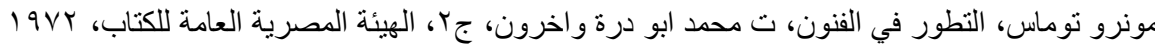

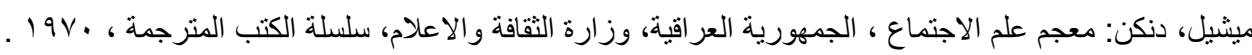
نبيلة أبراهيم، القصص الثعبي، مجلة مأثروات شعبية، المركز الفولكلوري لدول الخليج، قطر، العدد الثالث، 1919

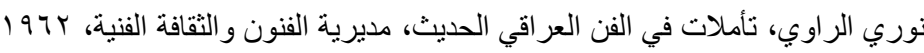

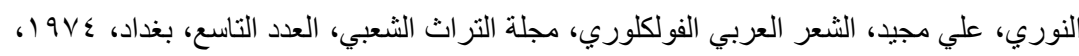
ويين جورج كولنجورد ، مباديء الفن، ترجمة: احمد حمدي محمود، مطبعة المعرفة، القاهرة، 977 ا.

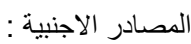

- $\quad$ Richard schechner: Environmental theater, new library of congress cataloging publication data, new york, first applause, 199 , p. ix.

- $\quad$ Richards Hooker, The Works of that Learned and Judicious, Pinine , mr. Hooker

- Thames\&Hudson: Dictionary of Art Terms.

http://www.birmingham.ac.uk/staff/profiles/gees/harrison-roy.aspx 